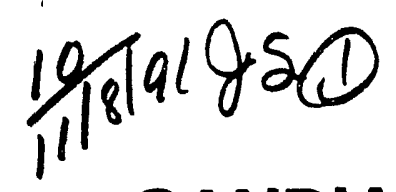

SANDIA REPORT

SAND91-1307 - UC -520

Unlimited Release

Printed October 1991

\title{
Analysis of Thermosyphoning in a Steam Generator Model
}

M. J. Martinez, G. M. Martinez

Proparod by

Sendia National Laboratories

Albuquerque, New Mexico 87185 and Livermore, Calltornia 94550

for the United States Department of Enorgy

under Contract DE-ACO4-760P00789

$+$

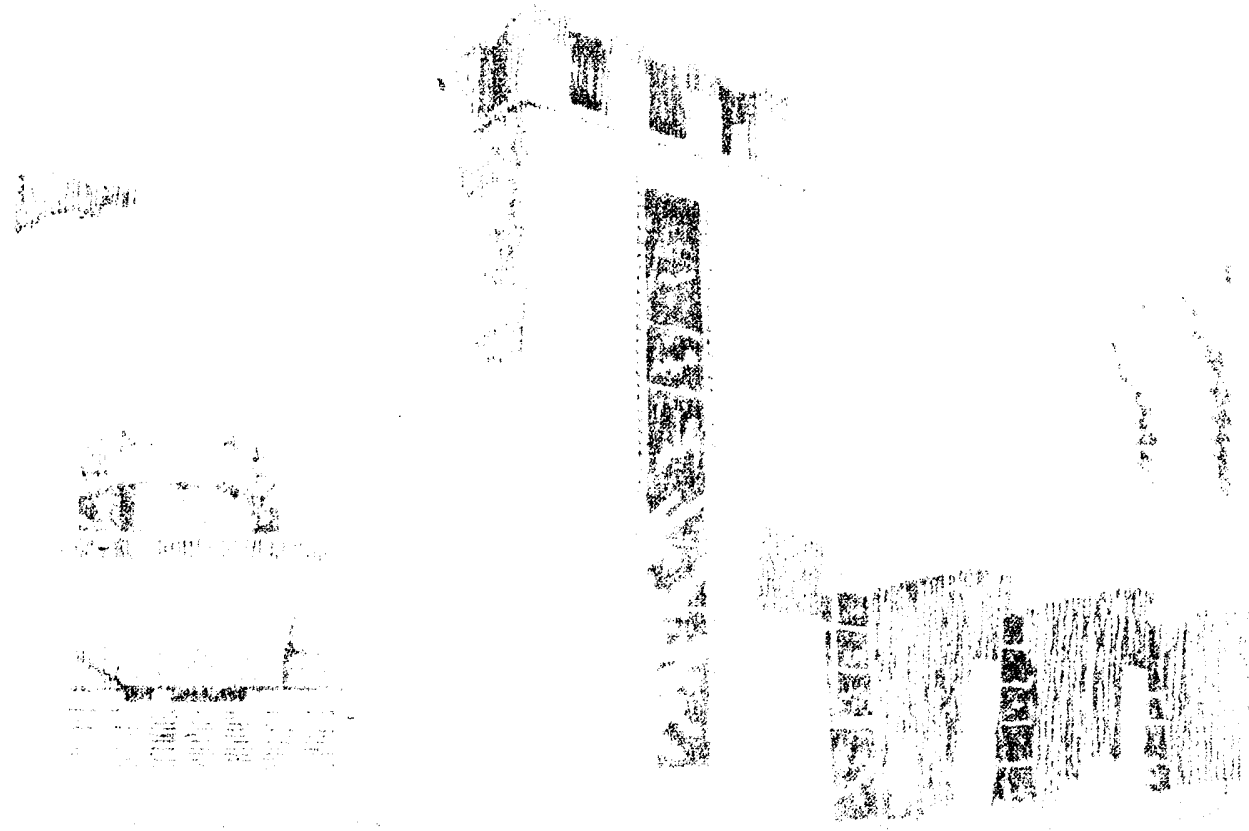

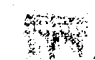


Issued by Sandia National Laboratories, operated for the United States Department of Energy by Sandia Corporation.

NOTICE: This report was prepared as an account of work sponsored by an agency of the United States Government. Neither the United States Government nor any agency thereof, nor any of their employees, nor any of their contractors, subcontractors, or their employees, makes any warranty, express or implied, or assumes any legal liability or responsibility for the accuracy, completeness, or usefulness of any information, apparatus, product, or process disclosed, or represents that its use would not infringe privately owned rights. Reference herein to any specific commercial product, process, or service by trade name, trademark, manufacturer, or otherwise, does not necessarily constitute or imply its endorsement, recommendation, or favoring by the United States Government, any agency thereof or any of their contractors or subcontractors. The views and opinions expressed herein do not necessarily state or reflect those of the United States Government, any agency thereof or any of their contractors.

Printed in the United States of America. This report has been reproduced directly from the best available copy.

Available to DOE and DOE contractors from

Office of Scientific and Technical Information

PU Box 62

Oak Ridge, TN 37831

Prices available from (615) 576-8401, FTS 626-8401

Available to the public from

National Technical Information Service

US Department of Commerce

5285 Port Royal Rd

Springfield, VA 22161

NTIS price codes

Printed copy: A03

Microfiche copy: A01 


\title{
Analysis of Thermosyphoning in a Steam Generator Model
}

\author{
M. J. Martinez \\ Computational Fluid Dynamics Division 1511 \\ and \\ G. M. Martinez \\ Thermal Hydraulics Division 6418 \\ Sandia National Laboratories \\ Albuquerque, New Mexico 87185
}

\begin{abstract}
An analysis of thermosyphoning in a steam generator model is presented. The model considers the transient development of buoyancy-driven steam flow in the steam generator tubing, secondary side heat transfer and an inlet plenum mixing model. Numerical solutions are obtained for conditions intended to simulate the natural circulation phenomena in a 3-Loop pressurized water reactor in a loss-of-coolant accident scenario. The relation between the circulation rate and the heating rate is determined. The sensitivity of the model to various key parameters is examined.
\end{abstract}




\section{Contents}

1 Introduction . . . . . . . . . . . . . . . . . . . . . . 6

2 Steam Generator Model . . . . . . . . . . . . . . . . . . 8

2.1 Assumptions and Approximations . . . . . . . . . . . . . 8

2.2 Thermosyphon Equations . . . . . . . . . . . . . . . . . . 9

2.3 Inlet Plenum Mixing Model . . . . . . . . . . . . . . . 11

2.4 Friction and Heat Transfer Correlations . . . . . . . . . . . 11

2.5 Thermophysical Properties and Dimensions . . . . . . . . . . 12

3 Numerical Treatment and Code Testing . . . . . . . . . . . . . 14

4 Discussion of Results . . . . . . . . . . . . . . . . . . . 14

4.1 Base Case Results . . . . . . . . . . . . . . . . . . . 15

4.2 Heating Rate Variation . . . . . . . . . . . . . . . . . 16

4.3 Mixing Fraction Variation . . . . . . . . . . . . . . . . 20

4.4 Tube Ratio Variation . . . . . . . . . . . . . . . . . 20

4.5 Mass Flow Ratio Variation . . . . . . . . . . . . . . . . 20

4.6 Influence of Loss Coefficients . . . . . . . . . . . . . . . 22

4.7 Influence of Secondary Heat Transfer . . . . . . . . . . . . 24

5 Conclusions . . . . . . . . . . . . . . . . . . . . . . 27

6 References . . . . . . . . . . . . . . . . . . . . . . . 29

\section{Tables}

2.1 Thermophysical Properties and Dimensions. . . . . . . . . . . 15 


\section{Figures}

1.1 Schematic of the steam generator model . . . . . . . . . . . . 7

2.1 Data fit for the expansion coefficient variation with temperature at $16 \mathrm{MPa}$. 13

2.2 Data fit for the steam density variation with temperature at $16 \mathrm{MPa}$. . . 13

2.3 Data fit for the kinematic viscosity variation with temperature at $16 \mathrm{MPa}$. 14

4.1 Temperature history for the base case. . . . . . . . . . . . . 17

$\begin{array}{lll}4.2 & \text { Steam generator mass flow rate variation with mass flow ratio, } m_{H L} / m_{S G} \text {. } \quad 17\end{array}$

4.3 Temperature history for $r=5.5 \mathrm{Kelvin} / \mathrm{min}$. . . . . . . . . . . 18

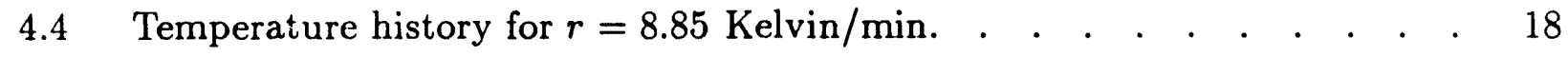

4.5 Temperature history for $r=16.2 \mathrm{Kelvin} / \mathrm{min}$. . . . . . . . . . . 19

4.6 Steam generator flow rate variation with heating rate. . . . . . . . . 19

4.7 Secondary side steam temperature history for various heating rates. . . . 21

4.8 Profiles of steam temperature for various heating rates. . . . . . . . 21

4.9 Variation of steam generator mass flow rate history with mixing fraction. . 22

4.10 Variation of steam generator mass flow rate history with the ratio of the number of forward-flowing to backward-flowing tubes. . . . . . . . 23

4.11 Temperature history for $m_{H L} / m_{S G}=2$. . . . . . . . . . . . . . . . . 23

4.12 Temperature history for $K=20$. $\quad$. . . . . . . . . . . . . . . . . . $\quad .25$

4.13 Effect of loss coefficient on steam generator flow rate. . . . . . . . 25

4.14 Effect of secondary side heat transfer on steam generator flow rate. . . . 26

4.15 Temperature history without secondary side heat transfer . . . . . . 26 


\section{Introduction}

An analysis of thermosyphoning in a steam generator model is presented. The model was developed in support of a review of work done in modeling the TMLB' accident scenario requested by the Nuclear Regulatory Commission (NRC). This represents a loss of coolant accident (LOCA.) scenario in which the return cold leg does not clear and blocks the return flow of superheated steam from the steam generators back to the vessel. This scenario was originally modeled by Bayless (1988) of the Idaho National Engineering Laboratory (INEL) using the SCDAP/RELAP5 (S/R5) computer code. Related simulations have been performed by Domanus and Sha (1988) and Cha, Domanus and Sha (1990) using the COMMIX code (Domanus et al. 1985). COMMIX is a three-dimensional finite difference code, the output of which is often used to calibrate systems codes to include mulidimensional effects. In particular, the model developed by Bayless of the TMLB' scenario was based in part on results computed by Domanus and Sha (1988).

A prominent feature in the simulation of this scenario is the postulated development of natural circulation of superheated steam in the steam generators once the core has been uncovered. Because the return cold leg does not clear, a natural circulation pattern is assumed to develop in which steam enters the top of the hot leg from the vessel, flows along the top of the hot leg to the inlet plenum where it mixes, flows through some fraction of the steam generator tubing to the outlet plenum, returns to the inlet plenum via the remaining tubes and returns to the vessel through the lower half of the hot leg, see Figure 1.1. An important aspect of simulating this phenomena is proper modeling of the circulation rate and the heat transfer rates in the steam generator, since heat removal in the stearn generator is the source of buoyancy driving the natural circulation phenomena.

The motivation for developing the thermosyphon model was twofoid: 1) to provide an independent investigation of the relation between steam temperatures in the inlet plenum and the steam generator circulation rate, and 2) to provide a computationally efficient model to study the effects of variation of key parameters affecting the circulation rate. The governing equations which model the thermosyhoning phenomena in the steam generator are developed from a mass, momentum and energy balance on the system. The resulting equations are similar to those presented in earlier studies of thermosyphons, including closed (e.g. Greif et al. 1979, Hart 1984) and open (e.g. Torrance 1979) loop thermosyphons. Stewart et al. (1986) and Sanders (1987) present similar models for natural circulation phenomena applicable to steam generators. Momentum conservation includes a balance of the rate of change of momentum with buoyancy and viscous forces in a typical tube. The buoyancy is treated via the Boussinesq approximation. The pressure drop over forward- and backward-flowing tubes is eliminated by an appropriate summation of these respective equations. The energy balances include storage, convection and heat exchange between the flowing vapor and the tubing. Heat exchange to the secondary side in the steam generator is modeled by treating the secondary side steam 


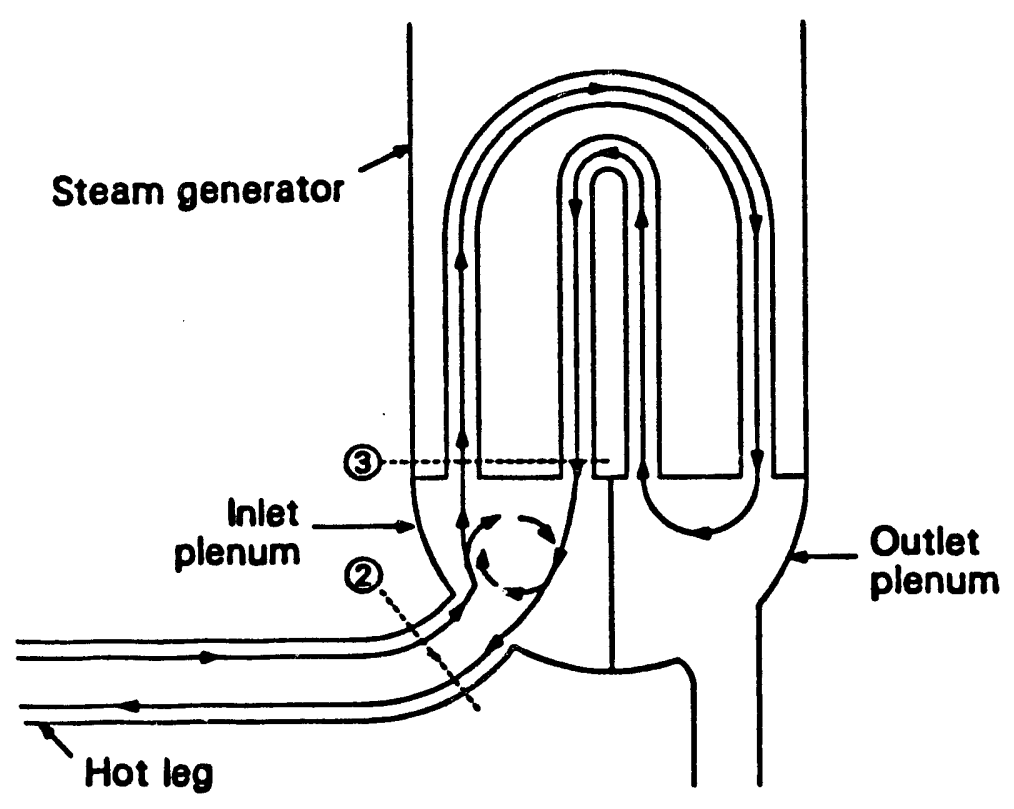

Figure 1.1. Schematic of the steam generator model

as a lumped volume. The resulting coupled system of equations is solved numerically for the steam generator circulation rate, the vapor and tubing temperature distributions along the length of the U-tubes, and the secondary side steam temperature.

The model is applied to simulate thermosyphoning in a steam generator representative of one of three such generators in a 3-Loop Westinghouse Pressurized Water Reactor (PWR). Only the thermosyphoning phenomena is considered in this model. The vessel and hot and cold legs which comprise the primary components in a PWR are not modeled explicitly. Their effect in producing and transporting steam vapor to the steam generator is modeled by specifying the heating rate of gases entering the inlet plenum from the top of the hot leg. Heating rate values are varied about values predicted with large systems codes which have been employed to model the entire PWR under the TMLB' transient.

To reiterate, the objective of this analysis was to provide an independent analysis, that is apart from those performed with the syscems codes SCDAP/RELAP5 and MELCOR (Summers et al. 1991), of the circulation rate in the steam generator during the TMLB' transient. Furthermore, the resulting model is much less CPU intensive that the systems codes and sensitivity studies can be performed in a much more cost effective manner. 


\section{Steam Generator Model}

In this work only the buoyancy-driven flow in the steam generator tubing is modeled in some detail. Mixing of gases in the plena and the counter-current flow in the hot leg are not treated explicitly. These effects are modeled by use of a thermodynamic mixing model developed by Stewart et al. (1986), which contains various mixing parameters whose influence is to be determined. The objective of this study was to develop a model which contains the essential mechanisms which generate the circulation in the steam generator, and not to address the complex flow that arises in the plena.

\subsection{Assumptions and Approximations}

There are several assumptions and approximations that were invoked in developing the model; these are enumerated below:

1. Temperature and velocity are assumed to depend only on distance along tubes, $x$, and on time, $t$, i.e., equations are area-averaged.

2. Boussinesq approximation is invoked.

3. Streamwise heat conduction is small compared to convection and is not included in gas energy balance.

4. Heat conduction is also neglected in piping. This invokes the small Biot number assumption since the pipe walls are thin.

5. Pipe bend is neglected.

6. Tube sheet is not modeled.

7. Temperature-dependent properties are based on average temperatures, $\bar{T}_{g}=\left(T_{g}(0, t)+\right.$ $\left.T_{g}(2 L, t)\right) / 2$, and $\bar{T}_{p}=\left(T_{p}(0, t)+T_{p}(2 L, t)\right) / 2$, where $T_{g}$ denotes the vapor temperature and $T_{p}$ is the steam generator tube temperature.

Rigorous adherence to the conditions under which the Boussinesq approximation is valid requires, at a minimum, that density variations over the temperature range in the problem are sufficiently small. Specifically,

$$
\left|\frac{\rho\left(T_{g}\right)-\rho\left(\bar{T}_{g}\right)}{\rho\left(\bar{T}_{g}\right)}\right| \ll 1
$$

is the first (asymptotic) requirement for validity of the Boussinesq approximation; other requirements also enter. Using the equation of state, for small variations in pressure, as we consider here, the above requirement can also be stated as

$$
\left|-\beta\left(T_{g}-\bar{T}_{g}\right)\right| \ll 1,
$$


where $\beta$ is the coefficient of thermal expansion. In the results to be presented shortly, this parameter is normally less than about 0.2 . The exception is for the highest heating rate considered, where the parameter approaches about 0.3 .

\subsection{Thermosyphon Equations}

A schematic of the sieam generator is shown in Figure 1.1. This schematic shows only one forward- and one backward-flowing tube, however, the steam gencrator modeled below includes a total of 3348 inverted U-shaped tubes. It is assumed that $n_{f}$ tubes carry steam from the inlet plenum to the outlet plenum, and that the remaining $n_{b}$ tubes carry the same total mass flow from outlet plenum back to the inlet plenum. The mass and momentum equations governing the buoyancy-driven flow in the steam generator are displayed below.

Mass:

$$
v=v(t), \quad \dot{m}_{S G}=n_{f} \rho_{g} v \frac{\pi}{4} d_{i}^{2}=n_{b} \rho_{g} u \frac{\pi}{4} d_{i}^{2}
$$

\section{Momentum:}

$$
\begin{gathered}
\rho_{g} L\left(1+\frac{n_{f}}{n_{b}}\right) \frac{d v}{d t}=\rho_{g} g \beta\left(\int_{0}^{L / 2}-\int_{L / 2}^{L}+\int_{L}^{3 L / 2}-\int_{3 L / 2}^{2 L}\right) T_{g}(x, t) d x \\
-2 C_{f} \rho_{g} v^{2} \frac{L}{d_{i}}
\end{gathered}
$$

where $C_{f}$ is the integrated friction coefficient,

$$
C_{f}=f(v)+\left(\frac{n_{f}}{n_{b}}\right)^{2} f(u) .
$$

The mass balance equation states that the velocity depends only on time, however, the momentum equation couples the velocity to the temperature distribution over the entire length of tubing. In these equations, $\rho_{g}$ is gas density, $d_{i}$ is the tubing inner diameter in the steam generator, $v$ is the velocity in a forward-flowing tube, $u$ is the velocity in a backward-flowing tube, $\beta$ is the coefficient of thermal expansion, and $L$ is the length of an inverted U-tube. The forward-flowing and backward-flowing momentum equations have been summed to eliminate the pressure drop from inlet to outlet plena, resulting in Eqn. (2.2). The forward-to-backward flowing tube ratio enters in this process by elimination of $u$ according to $n_{f} v=n_{b} u$, given in (2.1).

Energy balances for the steam flowing in the tubing and for the tubing matcrial itself are shown below.

Steam Energy Balance:

$$
\rho_{g} C_{p g}\left(\frac{\partial T_{g}}{\partial t}+v \frac{\partial T_{g}}{\partial x}\right)=-4 \frac{h_{i}}{d_{i}}\left(T_{g}-T_{p}\right), \quad 0 \leq x<L
$$


and,

$$
\rho_{g} C_{p g}\left(\frac{\partial T_{g}}{\partial t}+\frac{n_{f}}{n_{b}} v \frac{\partial T_{g}}{\partial x}\right)=-4 \frac{h_{i}}{d_{i}}\left(T_{g}-T_{p}\right), \quad L<x \leq 2 L
$$

\section{Pipe Energy Balance:}

$$
\rho_{p} C_{p p} \frac{\partial T_{p}}{\partial t}=4 \frac{h_{i}}{\delta\left(2+\delta / d_{i}\right)}\left(T_{g}-T_{p}\right)-4 \frac{h_{o} d_{o}}{d_{o}^{2}-d_{i}^{2}}\left(T_{p}-T_{s}\right), \quad 0 \leq x \leq 2 L,
$$

where, $\rho_{p}$ is the tubing material density, $C_{p g}$ and $C_{p p}$ are the steam and tubing heat capacities, $h_{i}$ and $h_{o}$ are heat transfer coefficients for the inner and outer surface of the tubing, respectively, $\delta=d_{o}-d_{i}$ is the tube thickness, $d_{o}$ is the outer tube diameter and $T_{s}$ is the steam temperature on the secondary side of the steam generator. As noted above, streamwise heat conduction is neglected compared to convection for the steam and is also neglected for the piping. This latter approximation is essentially a small Biot number assumption based on the thin piping relative to the length of piping (see Table 2.1).

Heat transfer from the tubes to steam on the secondary side is assumed to be entirely due to natural convection. The steam on the secondary side of the steam generator is modeled as a lumped volume. The energy balance reads,

$$
\rho_{s} C_{p s} V_{s} \frac{\partial T_{s}}{\partial t}=\pi d_{\circ}\left(n_{f} \int_{0}^{L} h_{o}\left(T_{p}-T_{s}\right) d x+n_{b} \int_{L}^{2 L} h_{o}\left(T_{p}-T_{s}\right) d x\right) .
$$

Note that in the current model $h_{o}=\operatorname{func}\left(\bar{T}_{p}-T_{s}\right)$, and so is independent of pathlength. Secondary side steam properties were evaluated at $350^{\circ} \mathrm{C}$ and $7.5 \mathrm{MPa}$ (properties taken from Kays and Crawford, 1980).

These equations are subject to the following initial conditions;

$$
\begin{gathered}
v(t=0)=v^{0}, \\
T_{g}(x, 0)=T_{p}(x, 0)=T^{0},
\end{gathered}
$$

and to the boundary condition

$$
T_{h}(t)=T^{0}+r t
$$

where $T_{h}$ denotes the steam temperature entering the inlet plenum from the top of the hot leg and $r$ is the heating rate of the incoming steam. The values of heating rate considered are 5.5, 8.85, and $16.2 \mathrm{Kelvins/n.} n$. The nominal value, taken to be 8.85 Kelvins/min, roughly matches the results of Bayless (1988) using S/R5. The lower value is from calculations done with COMMIX (Domanus and Sha, 1988), and matches the 
temperature history of gases into the steam generator tubes. The upper value is also from COMMIX, and represents the temperature history of steam entering the top of the hot leg at the reactor vessel.

The inlet plenum mixing model, to be discussed shortly, provides the coupling with $T_{h}$. This boundary condition specifies an assumed heating rate for the steam entering the inlet plenum. The model computes the resulting steam temperatures exiting the steam generator tubes after flowing to the exit plenum and returning to the inlet plenum.

In these simulations we used $T^{0}=620 \mathrm{~K}, v^{0}=0$. The system pressure was assumed constant at $16 \mathrm{MPa}$, the set point for prescure-operated relief valves in the system. This initial temperature corresponds to average temperatures in the steam generators as predicted by Bayless (1988) at 160 minutes into the simulation of the 'TMLB' transient.

\subsection{Inlet Plenum Mixing Model}

Flow in the inlet and outlet plena is a complicated three-dimensional flow (Cha et al. 1990) which is not explicitly modeled here. Instead, the thermodynamic mixing model proposed and verified by Stewart et al. (1986) is employed:

$$
\begin{gathered}
T_{m}=\frac{\left[f_{m i x} T_{g}(2 L, t)+\left(\frac{m_{H L}}{m_{S G}}-\left(1-f_{m i x}\right)\right) T_{h}\right]}{\left[\frac{m_{H L}}{m_{S G}}-\left(1-2 f_{m i x}\right)\right]}, \\
T_{g}(0, t)=\left(1-f_{m i x}\right) T_{h}+f_{m i x} T_{m}, \\
T_{c}=\frac{\left[\left(1-f_{m i x}\right) T_{g}(2 L, t)+\left(\frac{m_{H L}}{m_{S G}}-\left(1-f_{m i x}\right)\right) T_{m}\right]}{\frac{m_{H L}}{m_{S G}}} .
\end{gathered}
$$

In this model, $f_{m i x}$ represents the fraction of hot gas $\left(T_{h}\right)$ that mixes in the inlet plenum; the remainder $1-f_{m i x}$ goes directly to the steam generator tubes. $T_{m}$ represents the "mixing cup temperature" for the mixed gases in the inlet plenum. $T_{c}$ is the fluid temperature entering the bottom of the hot leg after mixing in the inlet plenum. This model also allows for a different flow rate in the steam generator compared to that in the hot leg.

\subsection{Friction and Heat Transfer Correlations}

Standard correlations for frictional losses and heat transfer were employed in the model. The friction factor was specified as 


$$
f(v)=\frac{2 \tau_{w}}{\rho_{g} v^{2}}= \begin{cases}16 / R e_{v} & R e_{v} \leq 1209 \\ 0.078 / R e_{v}^{1 / 4} & R e_{v} \geq 1209\end{cases}
$$

where $R e_{v}=\rho_{g} v d_{i} / \mu_{g}$. The expression for $f(u)$ is similar, obtained by replacing $v$ with $u$ in the above.

The heat transfer rate from the flowing steam to the piping is specified according to

$$
N u_{i}=\frac{h_{i} d_{i}}{k_{g}}= \begin{cases}4 & R e \leq 667 \\ 0.022 R e^{4 / 5} & R e \geq 667\end{cases}
$$

where the Reynolds number based on $v$ and $u$ is used for the forward- and backwardflowing tubes, respectively. The heat transfer from the tubing to the secondary side is assumed to be by natural convection. Hence, the secondary side Nusselt number is specified with respect to a Rayleigh number,

$$
N u_{o}=\frac{h_{o} d_{o}}{k_{g}\left(T_{s}\right)}=0.59 R a^{1 / 4}
$$

where $R a=g \hat{H}\left(\bar{T}_{p}-T_{s}\right) L_{c}^{3} / \nu_{g} \alpha_{g}$. Thermophysical properties for steam at $7.5 \mathrm{MPa}$ and $620 \mathrm{~K}$ were used in this expression. Normally, the characteristic length, $L_{c}$, would be the height of the tubes at the U-bend. However, this would assume an unimpeded boundary layer development about each tube. Owing to the close packing of tubes in the steam generator, boundary layer interference from adjacent tubes is likely. Depending on the degree of interference, the characteristic length may lie somewhere between the length of tubes and the distance between adjacent tubes. Due to lack of data on natural convection heat transfer characteristics in steam generators for this configuration, the characteristic length was set to one meter. We find that this value results in fairly effective heat transfer from the flowing steam to the secondary side. In order to address the uncertainty in this value, we also considered a simulation with completely insulated steam generator tubing, representing the opposite extreme in heat transfer. The results of this study will be discussed in the following.

\subsection{Thermophysical Properties and Dimensions}

Figures 2.1-2.3 show the variation with temperature of thermophysical properties which were specified in the model. The fact that the viscosity of steam (and all gases) increases with temperature will impact the mass flow rates that are predicted.

Table 2.1 gives the remaining properties and dimensions that were specified to model the 3-Loop Westinghouse PWR. 


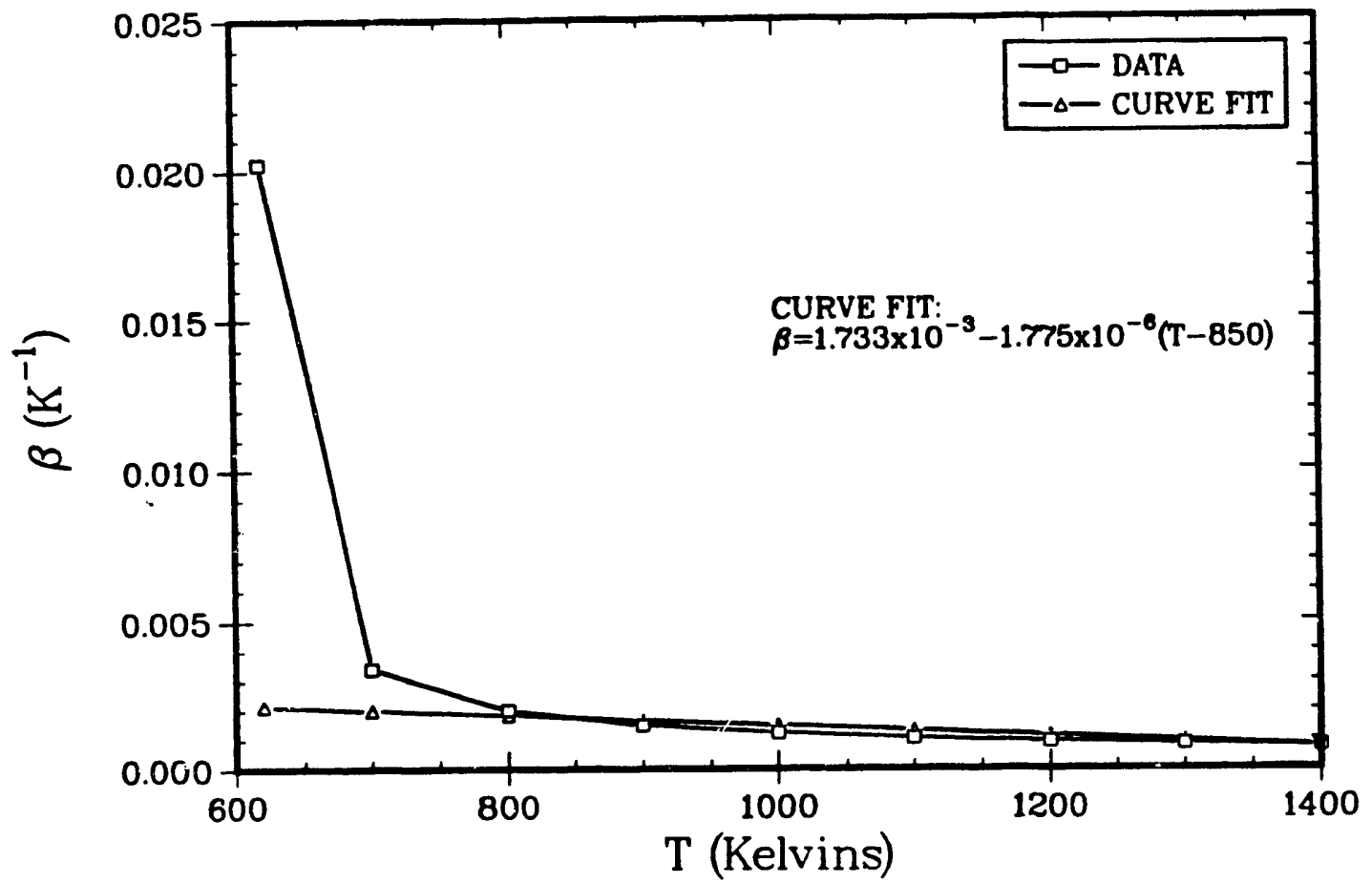

Figure 2.1. Data fit for the expansion coefficient variation with temperature at 16 MPa.

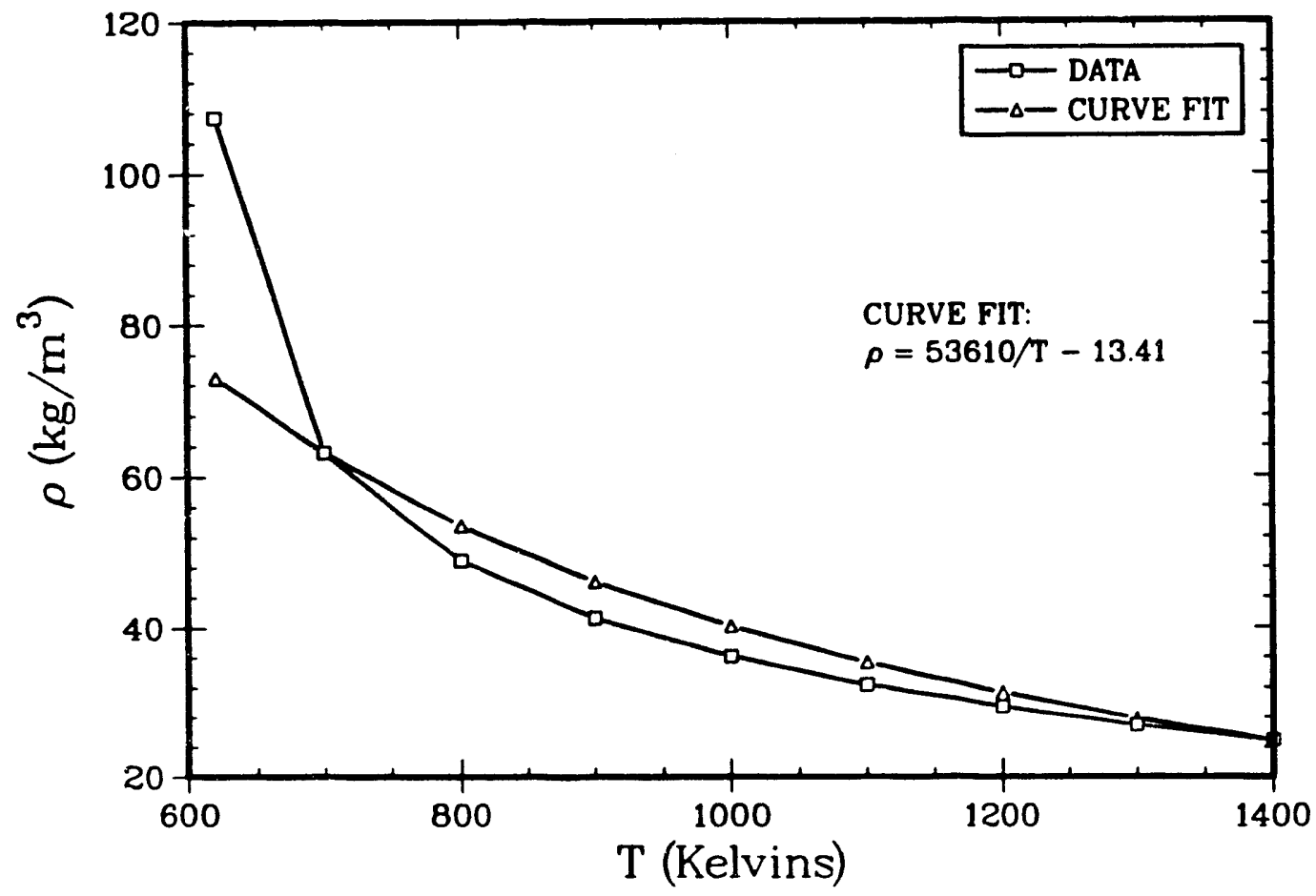

Figure 2.2. Data fit for the steam density variation with to nperature at $16 \mathrm{MPa}$. 


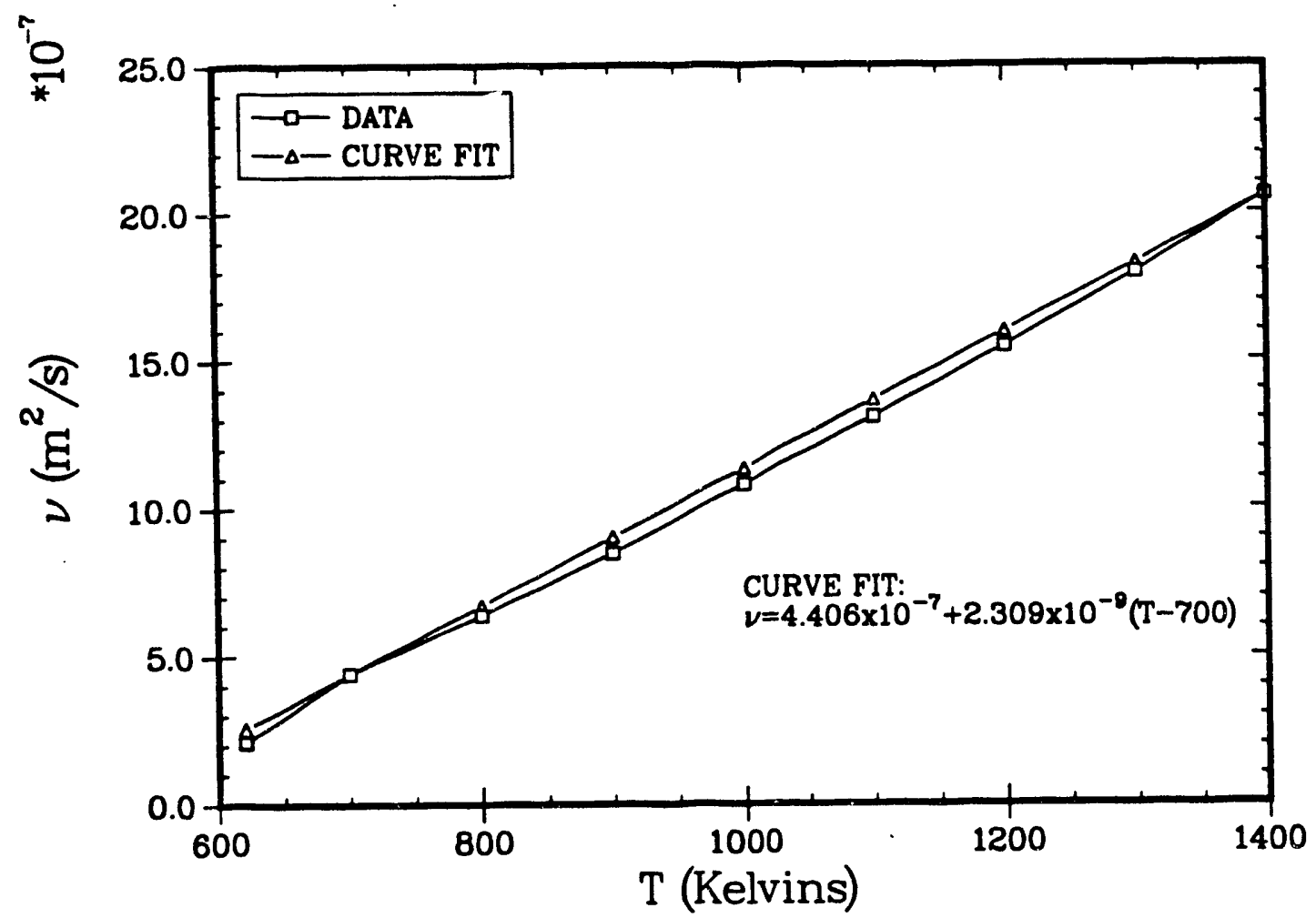

Figure 2.3. Data fit for the kinematic viscosity variation with temperature at 16 MPa.

\section{Numerical Treatment and Code Testing}

The thermosyphoning phenomena is described by Eqns (2.2)-(2.6), together with initial and boundary conditions. This system is solved numerically by the so-called Method-of-Lines (see Hyman, 1979). The technique is suitable for parabolic or hyperbolic systems, as we have here. The method simply involves discretizing the spatial dimensions by finite differences, resulting in a system of coupled nonlinear ordinary differential equations (ODEs). The ODEs are integrated in time by use of the stiff backward difference solver DEBDF (Shampine and Watts, 1980) available in the SLATEC mathematics library (Haskell, et al., 1980).

Based on a convergence study, it was determined that discretizing the spatial derivatives in the energy equations into 80 finite difference volumes was sufficient to obtain an accurate solution. Typical CPU requirements were about 4 seconds per simulation on the CRAY-YMP.

\section{Discussion of Results}

The major parameters considered in the study include the heating rate, $r$, the mixing fraction $f_{\text {mix }}$, the ratio of forward-running to backward-running tubes in the steam generator, $n_{r}=n_{f} / n_{b}$, and the ratio of mass flow rate in the hot leg to the steam gen- 
Table 2.1. Thermophysical Properties and Dimensions.

\begin{tabular}{|c|c|c|}
\hline \hline \multirow{3}{*}{ Parameter } & Value & Dimensions \\
\hline \multicolumn{3}{|c|}{ Steam } \\
\hline$k_{g}$ & 0.0998 & $\mathrm{~W} / \mathrm{m} / \mathrm{K}$ \\
\hline \multicolumn{3}{|c|}{ Secondary Side Steam } \\
\hline$\rho_{s}$ & 29 & $\mathrm{~kg} / \mathrm{m}^{3}$ \\
$C_{p s}$ & $0.3129 \times 10^{4}$ & $\mathrm{~J} / \mathrm{kg} / \mathrm{K}$ \\
$k_{s}$ & 0.0606 & $\mathrm{~W} / \mathrm{m} / \mathrm{K}$ \\
\hline \multicolumn{3}{|c|}{ Steam Generator Tubing } \\
\hline$\rho_{p} C_{p p}$ & $0.3502 \times 10^{7}$ & $\mathrm{~J} / \mathrm{m}^{3} / \mathrm{K}$ \\
\hline \multicolumn{3}{|c|}{ Dimensions } \\
\hline$V_{s}$ & 166 & $\mathrm{~m}$ \\
$L$ & 22 & $\mathrm{~m}$ \\
$d_{i}$ & 0.01968 & $\mathrm{~m}$ \\
$d_{o}-d_{i}$ & 0.001215 & $\mathrm{~m}$ \\
\multicolumn{3}{|c|}{} \\
\hline \hline
\end{tabular}

erator, $m_{r}=m_{H L} / m_{S G}$. The parameter set will be referred to collectively as the vector $\Pi=\left(r, f_{\text {mix }}, n_{r}, m_{r}\right)$. The base set was chosen as $(8.85,0.9,0.54,0.5)$. This heating rate, expressed in Kelvins/min, mixing fraction, tube ratio and mass flow ratio all match the results of Bayless.

\subsection{Base Case Results}

Figure 4.1 shows the temperature history for the base case over an $80 \mathrm{~min}$ (elapsed time) simulation period. The steam and piping temperature histories at various locations in tho system are shown on this and subsequent figures. $T_{h}$ is the steam temperature entering the inlet plenum from the hot leg, which in this model is a result of the heating rate accordin ${ }_{5}^{-}$to $(2.9)$. $T_{c}$ is the steam temperature after circulating in the steam generator, returning is the inlet plenum, mixing, and re-entering the lower half of the hot leg. $T_{g}(0)$ and $T_{p}(U)$ ire the steam and tubing temperatures, respectively, at the inlet to the steam generator tubing from the inlet plenum, and $T_{g}(2 L)$ and $T_{p}(2 L)$ are the exiting values after circulating in the steam generator. $T_{h t}$ and $T_{c t}$ are the steam temperatures entering and leaving the steam generator tubing computed by Domanus and Sha (1988) using COMMIX; these correspond to $T_{g}(0)$, and $T_{g}(2 L)$, respectively. The incoming steam temperature to the steam generator ( $\mathrm{SG}$ ) compares well with that computed by Domanus and Sha, however, the exiting temperature computed here is higher. The mass flow rate in the SG is shown in Figure 4.2 for various values of $m_{r}$. The history computed with COMMIX is also shown for comparison and the figure shows the flow rate 
computed here is substantially higher (almost double). This could explain the increased temperatures of gases exiting the SG in our calculation as compared to COMMIX. It is also emphasized that the simulations by Domanus and Sha (1988) using COMMIX assumed insulated SG tubing, i.e., heat transfer to the secondary side was not allowed.

The steam generator flow rate history shown in Figure 4.2 for $m_{r}=0.5$ is similar to that reported by Bayless. ${ }^{1}$ However, the heat transfer rate to the secondary side computed here appears to be vastly different from that predicted by Bayless. This is inferred from the histories of vapor temperatures in the hot leg reported by Bayless showing a temperature difference of roughly $580 \mathrm{~K}$ at 240 minutes. Vapor temperatures across the SG (i.e., $T_{g}(0)-T_{g}(2 L)$ ) were not reported by Bayless, however calculations of this problem with MELCOR (Martinez et al., 1991) show the temperature difference over the hot leg (i.e., $T_{h}-T_{c}$ ) to be much smaller than that across the SG, implying a temperature difference across the SG of greater than $580 \mathrm{~K}$. Under quasisteady conditions, the temperature difference $T_{g}(0)-T_{g}(2 L)$, multiplied by the heat capacity is the amount of heat being transferred to the secondary side. Figure 4.1 shows a temperature difference across the SG of only about $130 \mathrm{~K}$ at 240 minutes. Thus, the present model, when compared to Bayless' calculation with S/R5, predicts a similar mass flow rate for the SG but much lower temperature drop across the SG, implying a lower heat transfer rate to the secondary side.

On the other hand, these circulation rates are almost twice as high as were computed by Domanus and Sha using COMMIX. We can only speculate as to the reason for discrepancies in steam generator mass flow rates between our results and COMMIX. However, their specification of insulated tubing and the very coarse discretization of the steam generator model (Domanus and Sha, 1988) are possible reasons. We consider the effect of insulated tubes in the following and find some reduction in SG flow rate, but not to the level given by COMMIX. In this regard, it should be noted that our model assumes a heating rate for gases entering the inlet plenum whereas in the full model the temperature of incoming steam is fully coupled to the overall system behavior.

In the remainder of this section we consider how the performance of the steam generator model varies with the parameters.

\subsection{Heating Rate Variation}

Figures 4.3 through 4.5 show the temperature histories for various values of heating rate. The mass flow ratio is unity for these figures. Beyond the obvious increase in temperatures with heating rate, the figures also show that the difference between inlet and outlet SG temperatures increases with $r$. At $t=240 \mathrm{~min}$, these temperature differences are roughly 90,160 and $330 \mathrm{~K}$ for heating rates of $5.5,8.85$, and $16.2 \mathrm{Kelvins} / \mathrm{min}$, respectively. The temperature difference is about proportional to the heating rate.

\footnotetext{
${ }^{1}$ Bayless does not show the mass flow rate in the SG, but reports it to be about $120 \%$ higher than in the hot leg, which is shown.
} 


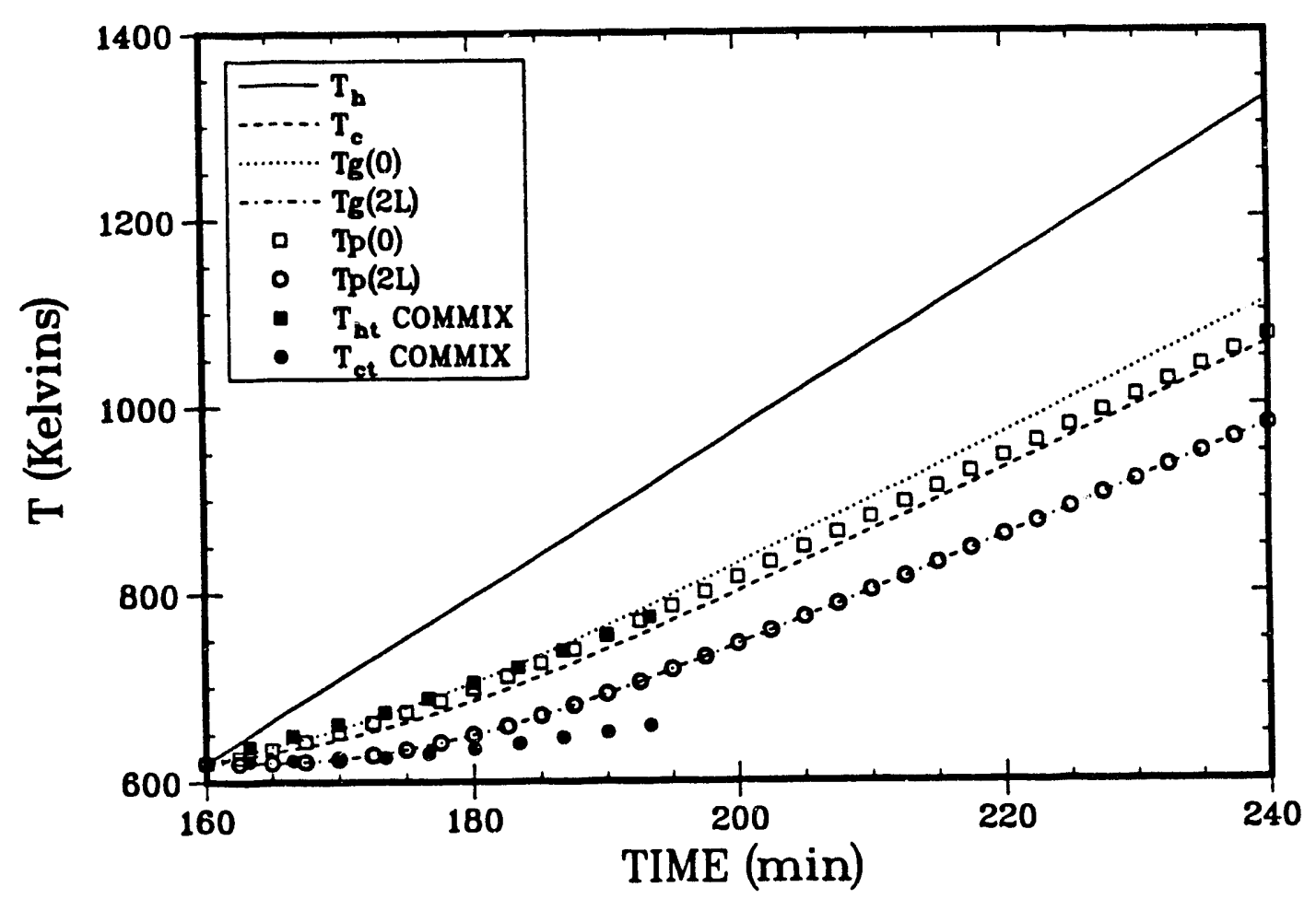

Figure 4.1. Temperature history for the base case, $\Pi=(8.85,0.9,0.54,0.5)$.

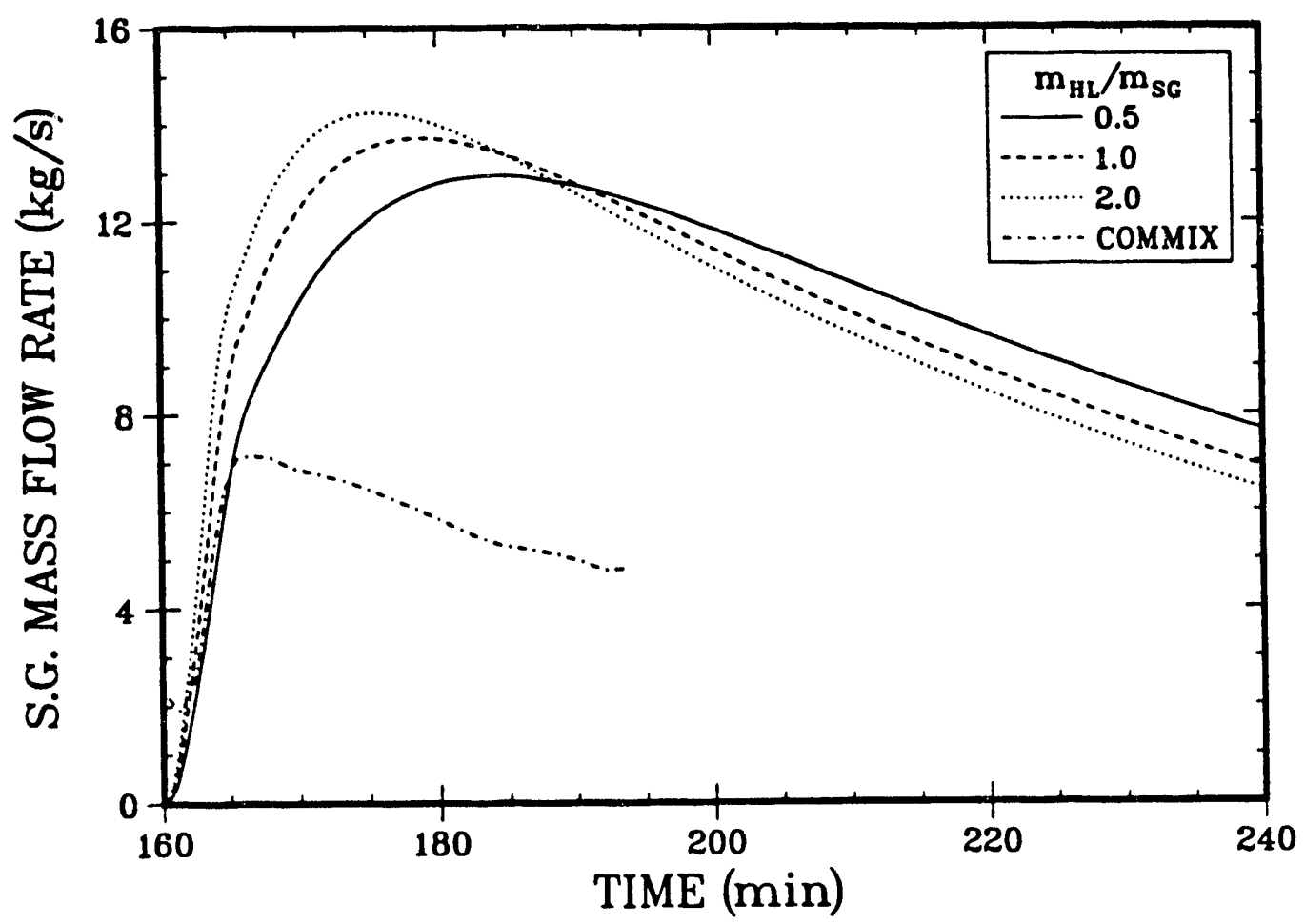

Figure 4.2. Steam generator mass flow rate variation with mass flow ratio, $m_{H L} / m_{S G}$, for $\Pi=(8.85,0.9,0.54$, variable $)$. 


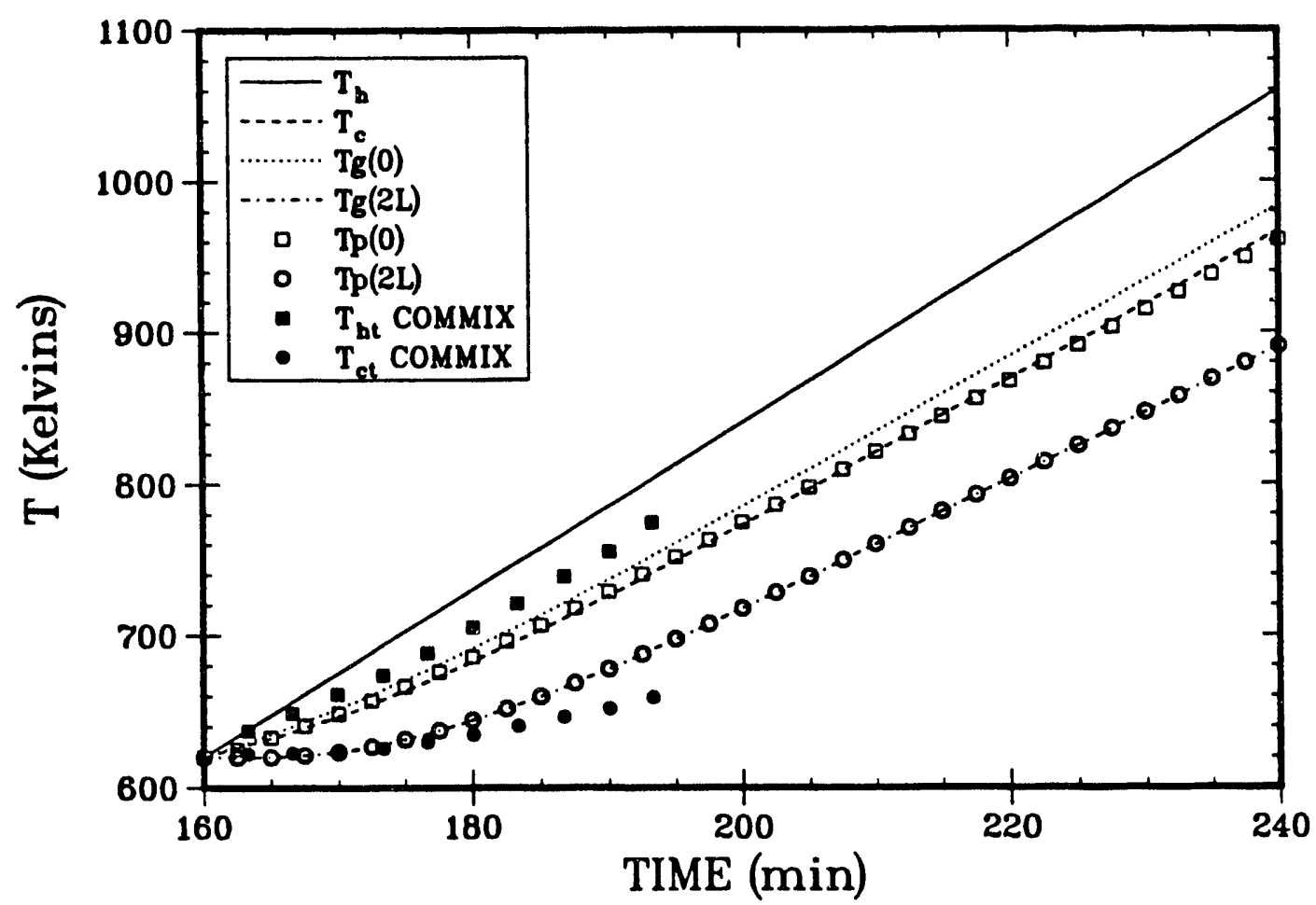

Figure 4.3. Temperature history for $r=5.5 \mathrm{Kelvin} / \mathrm{min}, \Pi=(5.5,0.9,0.54,1.0)$.

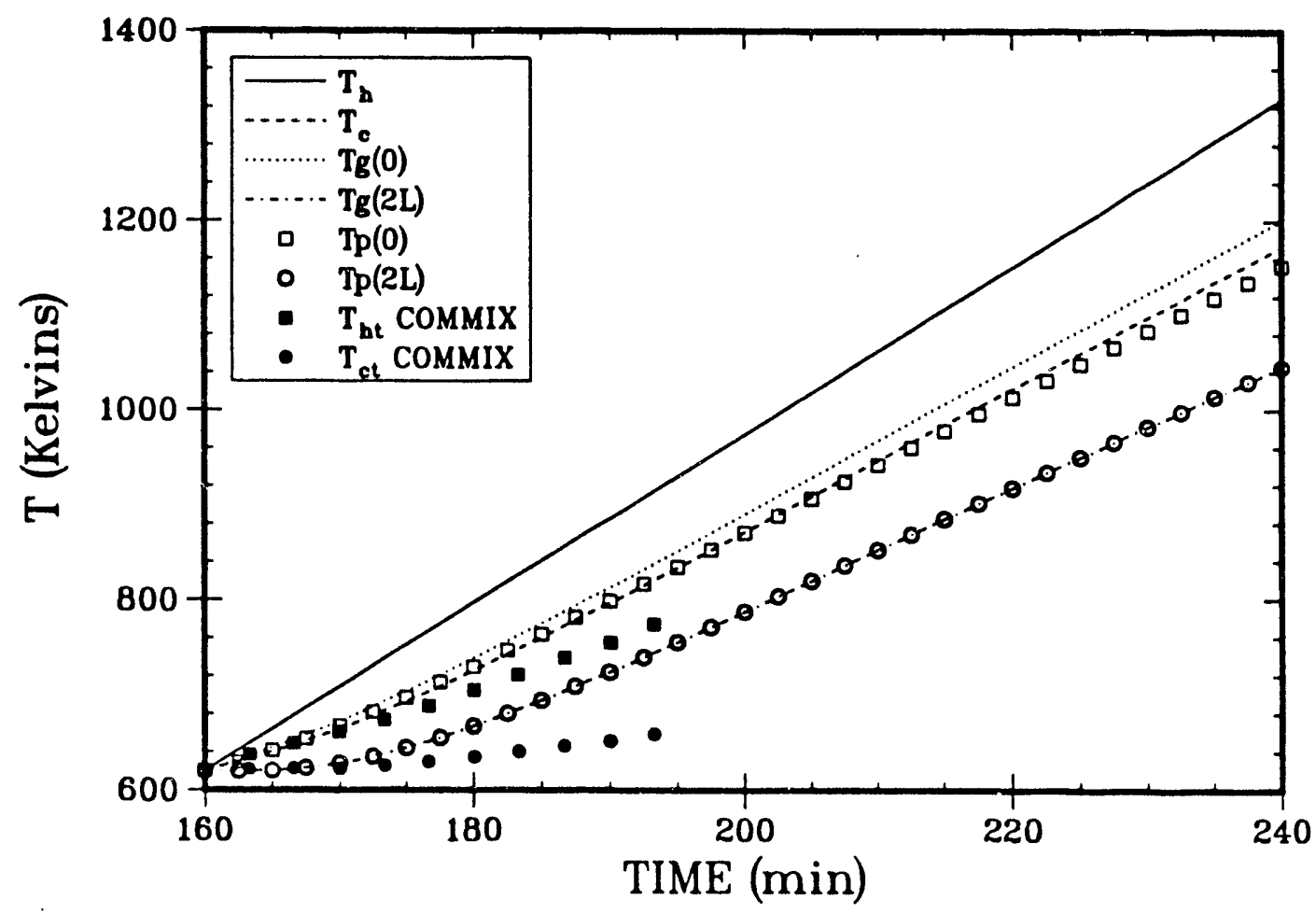

Figure 4.4. Temperature history for $r=8.85 \mathrm{Kelvin} / \mathrm{min}, \boldsymbol{\Pi}=(8.85,0.9,0.54,1.0)$. 


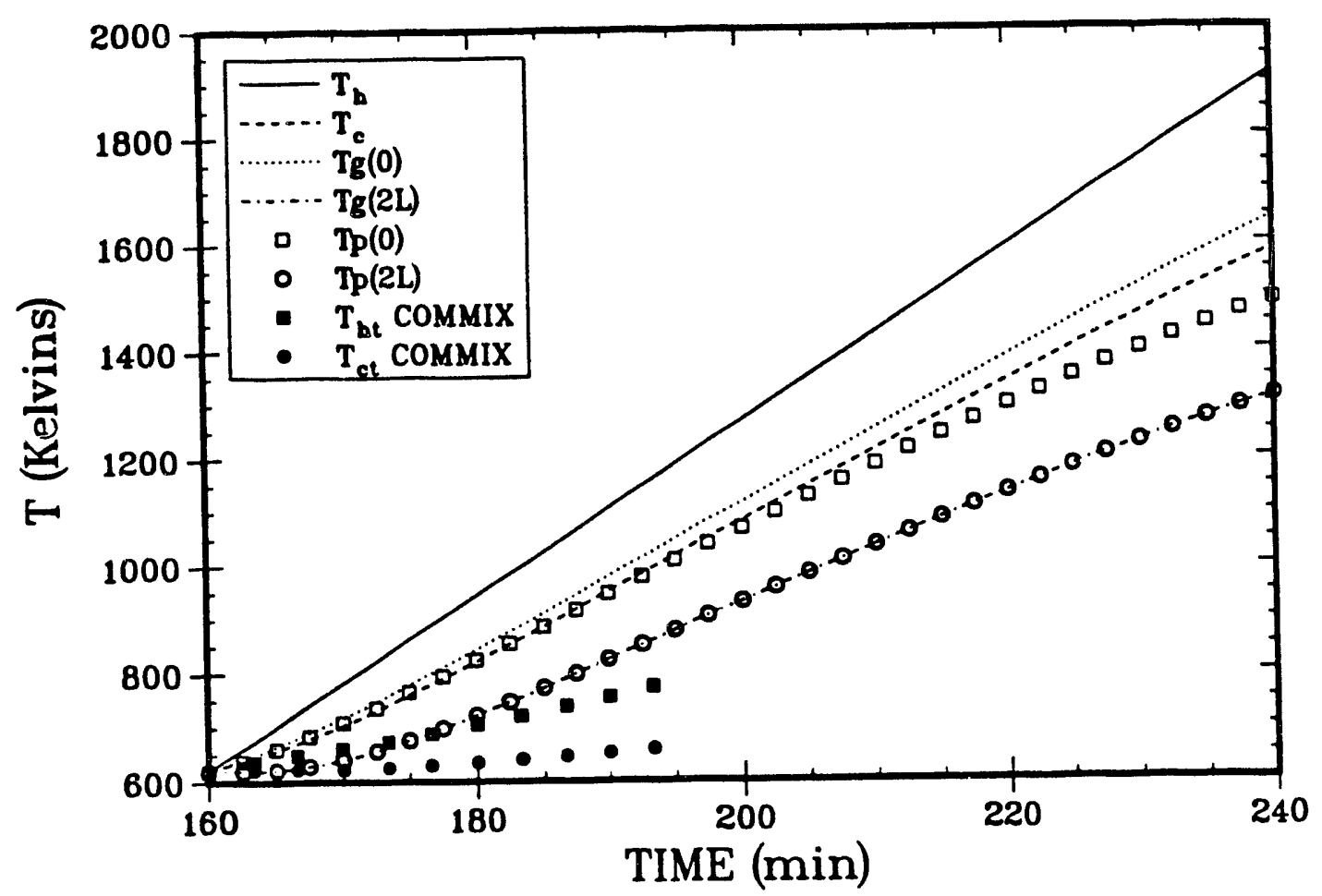

Figure 4.5. Temperature history for $r=16.2 \mathrm{Kelvin} / \mathrm{min}, \Pi=(8.85,0.9,0.54,1.0)$.

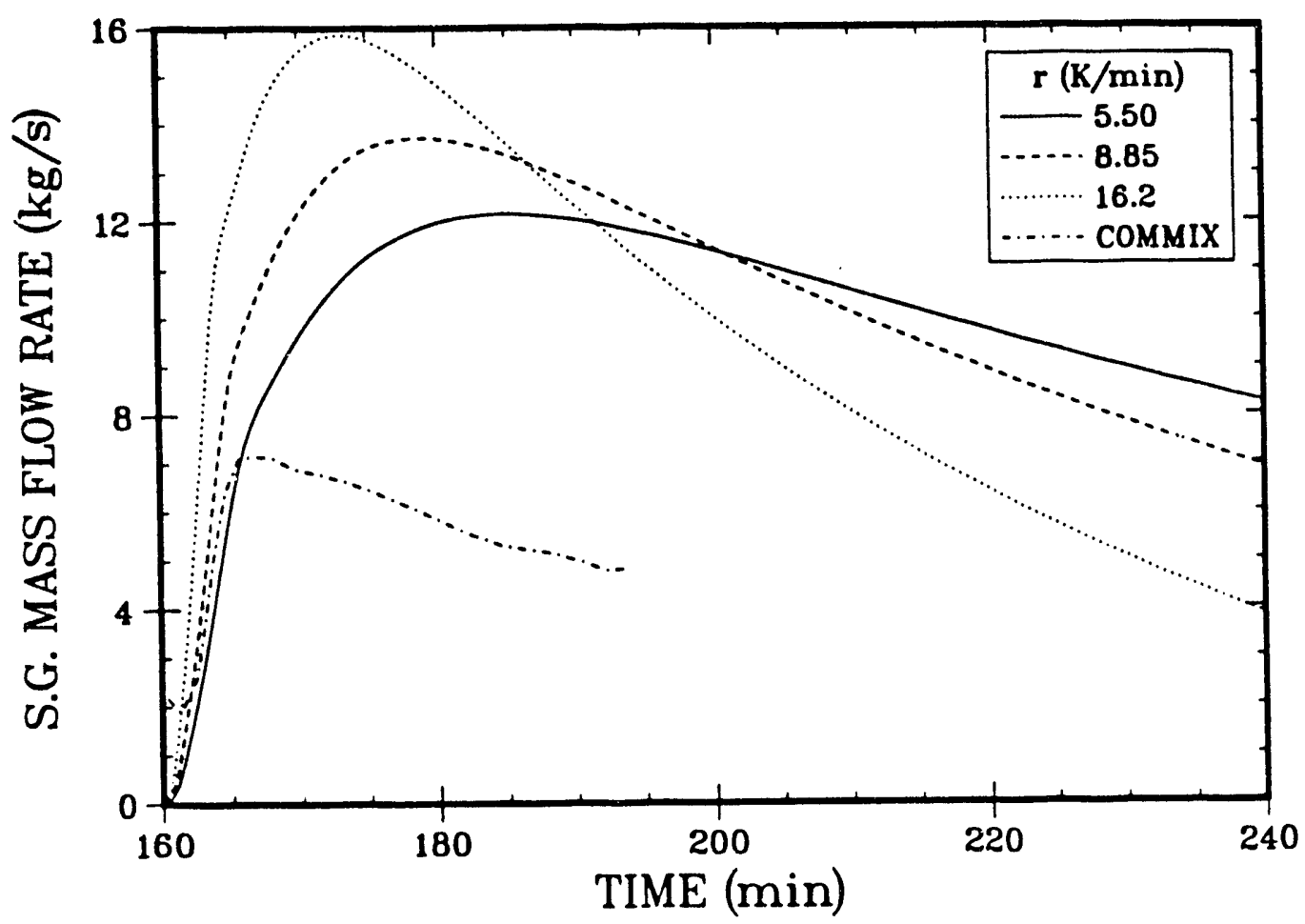

Figure 4.6. Steam generator flow rate variation with heating rate, $\Pi=($ variable $, 0.9,0.54,1.0)$. 
The varip: $n$ in SG mass flow rate with heating rate is shown in Figure 4.6. The maximum mass flow rate increases with heating rate, however, the mass flow rate decreases more rapidly with time for larger heating rates. This effect is due to the temperaturedependent steam properties, in particular, the decrease of steam density and increase in steam viscosity with temperature. Generally, as the heating rate is increased, the average steam temperatures also increase. Hence, higher $r$ initially increases the flow rate in the early transient, but as the entire gas volume is hotter, and therefore more viscous, the flow rate decreases as the drag increases with viscosity and the vapor density decreases with temperature. This is the reason for the flow rate decrease with time that is apparent in all mass flow rate histories.

The temperature history of the secondary side steam temperature volume is shown in Figure 4.7. The secondary side temperature increases in proportion to the heating rate.

Profiles of steam temperature variation with distance along the tubes for $t=240$ minutes are shown in Figure 4.8. The figure shows that the secondary cooling rate is high enough to cool the gas to a uniform value in the rising leg of the forward-running tubes $(x=11 \mathrm{~m})$. The temperature is uniform thereafter. Also, the temperature gradient is more localized to the entrance region as the heating rate increases. All plots show $T_{g}(2 L)=T_{p}(2 L)$.

\subsection{Mixing Fraction Variation}

The variation of SG mass flow rate with mixing fraction, $f_{m i x}$, is shown in Figure 4.9. The SG thermosyphoning rate is not sensitive to the mixing fraction for this set of parameters.

\subsection{Tube Ratio Variation}

The variation in the SG mass flow rate with the ratio of the number of forwardflowing tubes to backward-flowing tubes is shown in Figure 4.10 for $n_{r}=0.25,0.54$ and 0.75 , and for $m_{r}=0.5$. Only values of $n_{r}<1$ are considered since all experiments have reported this range. This is also expected since the forward-flowing tubes provide most of the buoyant head as shown in Figure 4.8, and thus less forward-flowing tubes than backward-flowing tubes are required. Figure 4.10 shows that the tube ratio is not significant until $n_{r} \approx .25$, i.e., the variation in flow rate between $n_{r}=0.75$ and 0.54 is much less than between 0.54 and 0.25 .

\subsection{Mass Flow Ratio Variation}

Figure 4.11 shows the temperature history for $\Pi=(8.85,0.9,0.54,2)$. By comparing with Figures 4.1 and 4.4 , one concludes that steam temperatures increase with increases 




Figure 4.7. Secondary side steam temperature history for various heating rates, $\Pi=($ variable $, 0.9,0.54,1.0)$.

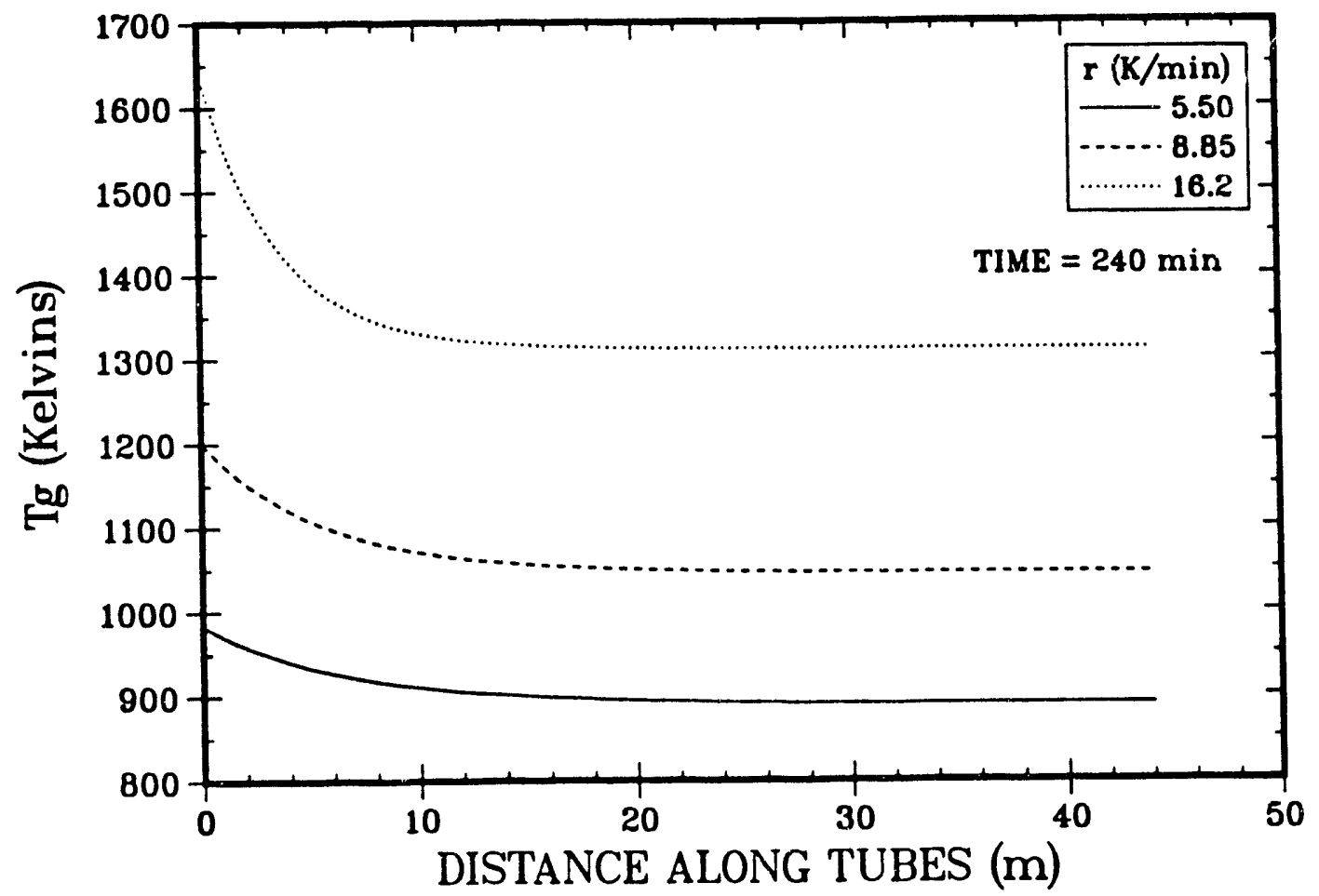

Figure 4.8. Profiles of steam temperature for various heating rates, $\Pi=($ variable $, 0.9,0.54,1.0)$. 


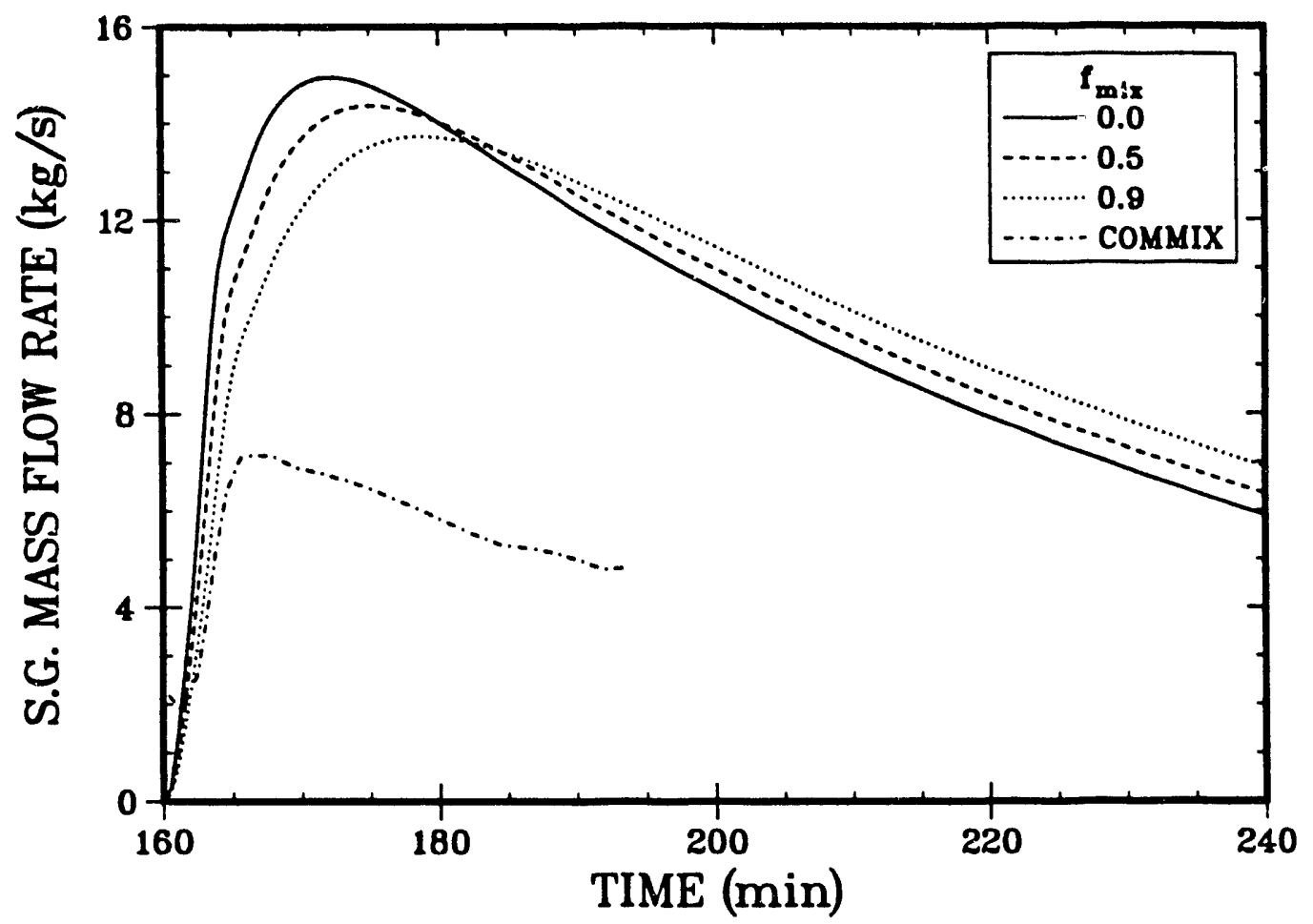

Figure 4.9. Variation of steam generator mass flow rate history with mixing fraction, $\Pi=(8.85$, variable, $0.54,1.0)$.

in the mass flow ratio. This is because with increasing $m_{r}$, more hot gases are cycled through the inlet plenum, thereby raising the average temperatures therein. Furthermore, with $m_{r}>1$ a larger fraction of these gases simply mix in the inlet plenum and return to the hot leg without circulating in the SG where the steam would be further cooled by heat exchange with the secondary side. Values obtained with $m_{r}=0.5$ match best with the values computed with COMMIX. One might expect $m_{r}<1$ since SG thermosyphoning should be the driving force to general recirculation. However, a temperature difference across a horizontal channel will also give rise to a circulation pattern (e.g. Bejan and Rossie, 1981), thereby motivating consideration of $m_{r}>1$.

The circulation rate in the SG was shown earlier in Figure 4.2. The figure shows moderate variation with $m_{r}$. The maximum flow rate increases with increasing $m_{r}$, however, the reverse is true at $t=240 \mathrm{~min}$. This latter effect is due to viscosity variations with temperature as discussed earlier.

\subsection{Influence of Loss Coefficients}

In his analysis using S/R5, Bayless specified a large loss coefficient for the hot leg and steam generator piping. Apparently, this was done to match the heat transfer rates reported by Domanus and Sha (1988) using COMMIX. It is also of interest here to determine the possible influence of such a specification in the present model. As we 


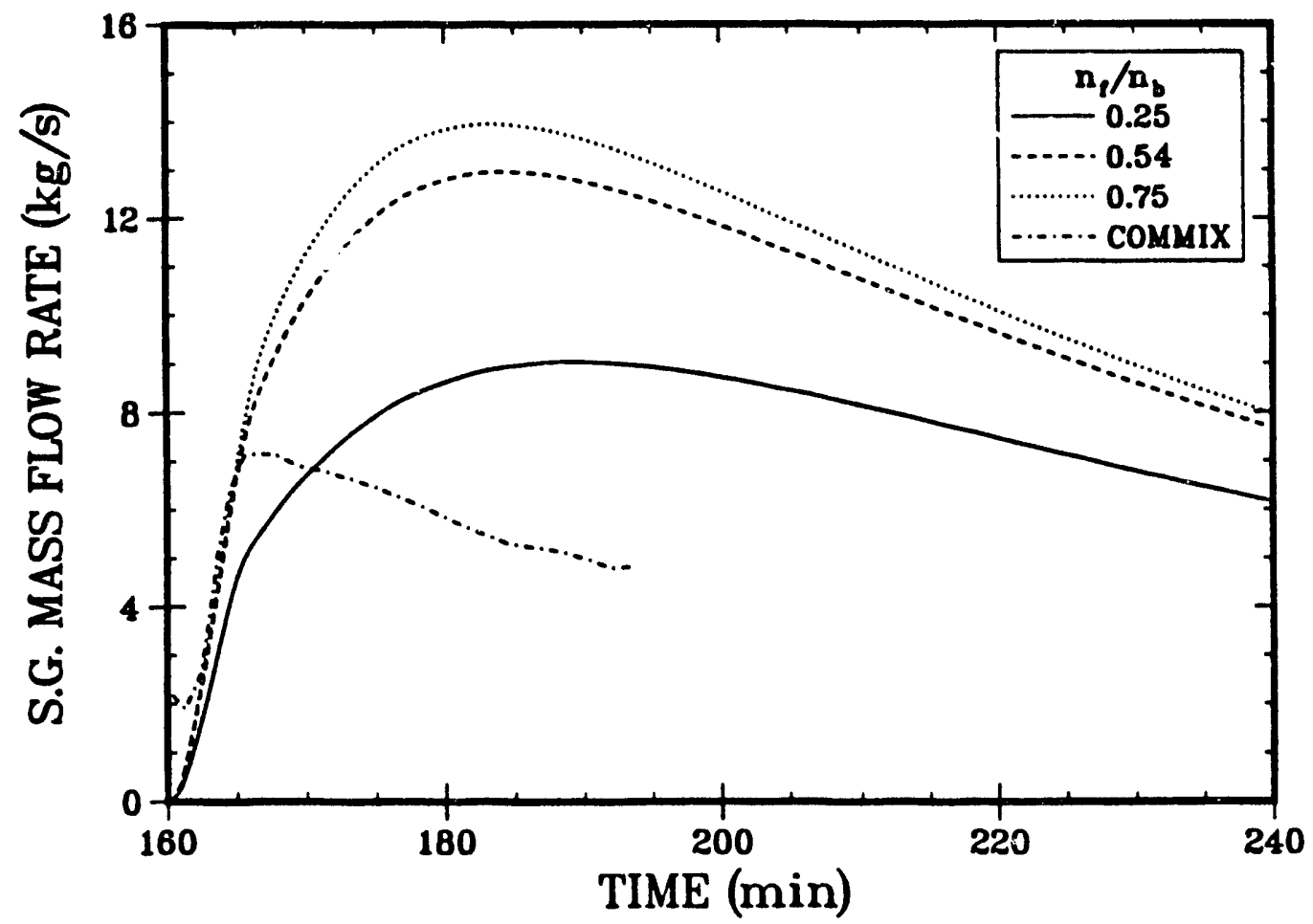

Figure 4.10. Variation of steam generator mass flow rate histury with $n_{r}=n_{f} / n_{b}$, $\Pi=(8.85,0.9$, variable, 0.5$)$.

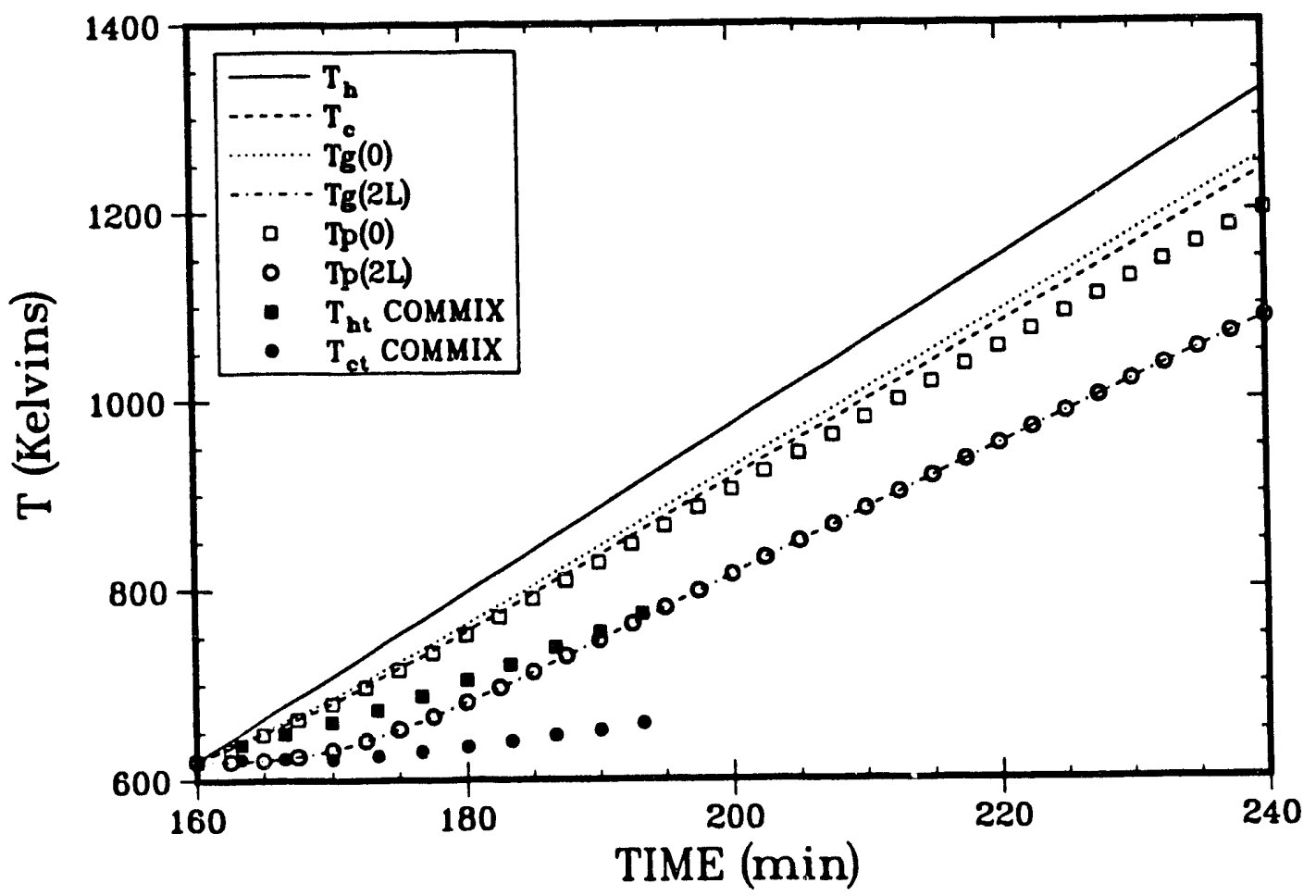

Figure 4.11. Temperature history for $m_{H L} / m_{S G}=2, \Pi=(8.85,0.9,0.54,2)$. 
stated earlier, the thermosyphon model predicts a similar flow rate history in the SG to that reported by Bayless. These flow rates are substantially higher than produced by the simulation of the TMLB' scenario using COMMIX, the simulation of which was used by Bayless to calibrate his model.

The loss coefficient was defined in the present model by specifying an effective friction factor. After accounting for the summing of forward- and backward-flowing tubes, the effective friction coefficient is

$$
C_{f}=f(v)+\left(\frac{n_{f}}{n_{b}}\right)^{2} f(u)+\frac{1}{2} K\left(1+\left(\frac{n_{f}}{n_{b}}\right)^{2}\right) \frac{d_{i}}{2 L},
$$

which replaces the one defined earlier following Eqn (2.2).

Figure 4.12 shows the temperature history using a value of $K=20$. This value is being used in MELCOR simulations of the TMLB' scenario (Martinez et al., 1991). Comparing with Figure 4.1 for the same parameter set but without a loss coefficient, one can see that the steam temperature exiting the SG is closer to the COMMIX values with a loss coefficient. Furthermore, while the overall steam temperatures are reduced with the loss coefficient specified, the teinperature difference between incoming and exiting SG steam is only slightly higher than without a loss coefficient, about $135 \mathrm{~K}$ in Figure 4.12 .

The mass flow rate in the SG is compared in Figure 4.13 with and without a specified loss coefficient. As might be expected, the loss coefficient reduces the mass flow rate. The reduction amount depends on time, but is roughly $10-25 \%$ less with $K=20$.

\subsection{Influence of Secondary Heat Transfer}

As we noted earlier, the calculations of Domanus and Sha (1988) using COMMIX assumed insulated SG tubing. Bayless calibrated his S/R5 model using this simulation. We also considered the specification of insulated SG tubing in our model in order to investigate its effect. Figure 4.14 compares the mass flow rate history with and without secondary side heat transfer in the SG. The latter is accomplished simply by setting $h_{o}=0$. The mass fivin rate is reduced by roughly $15-20 \%$. The oscillations in the history for insulated tubes mark the time when the temperature pulse reaches the outlet plenum and then the inlet plenum. The mass flow rate with insulated tubes is still considerably higher than that computed with COMMIX.

Figure 4.15 shows the temperature history with insulated SG tubes. Comparison with Figure 4.1 shows that in the absence of secondary side heat exchange, the circulating vapor is hotter overall but the temperature difference across the $\mathrm{SG}$ is less, about $100 \mathrm{~K}$ compared to $125 \mathrm{~K}$ with secondary side heat transfer. 


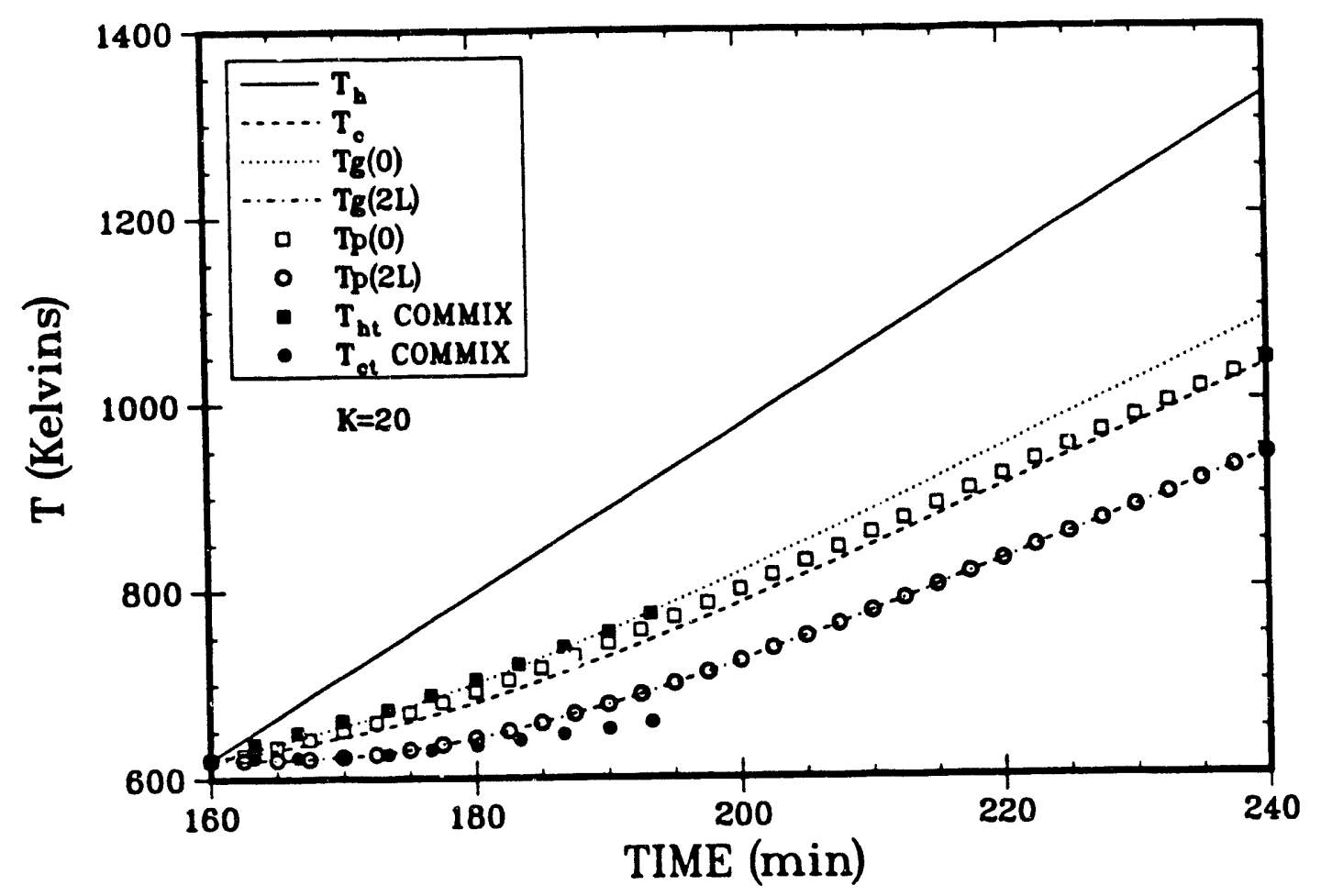

Figure 4.12. Temperature history for $K=20, \Pi=(8.85,0.9,0.54,0.5)$.

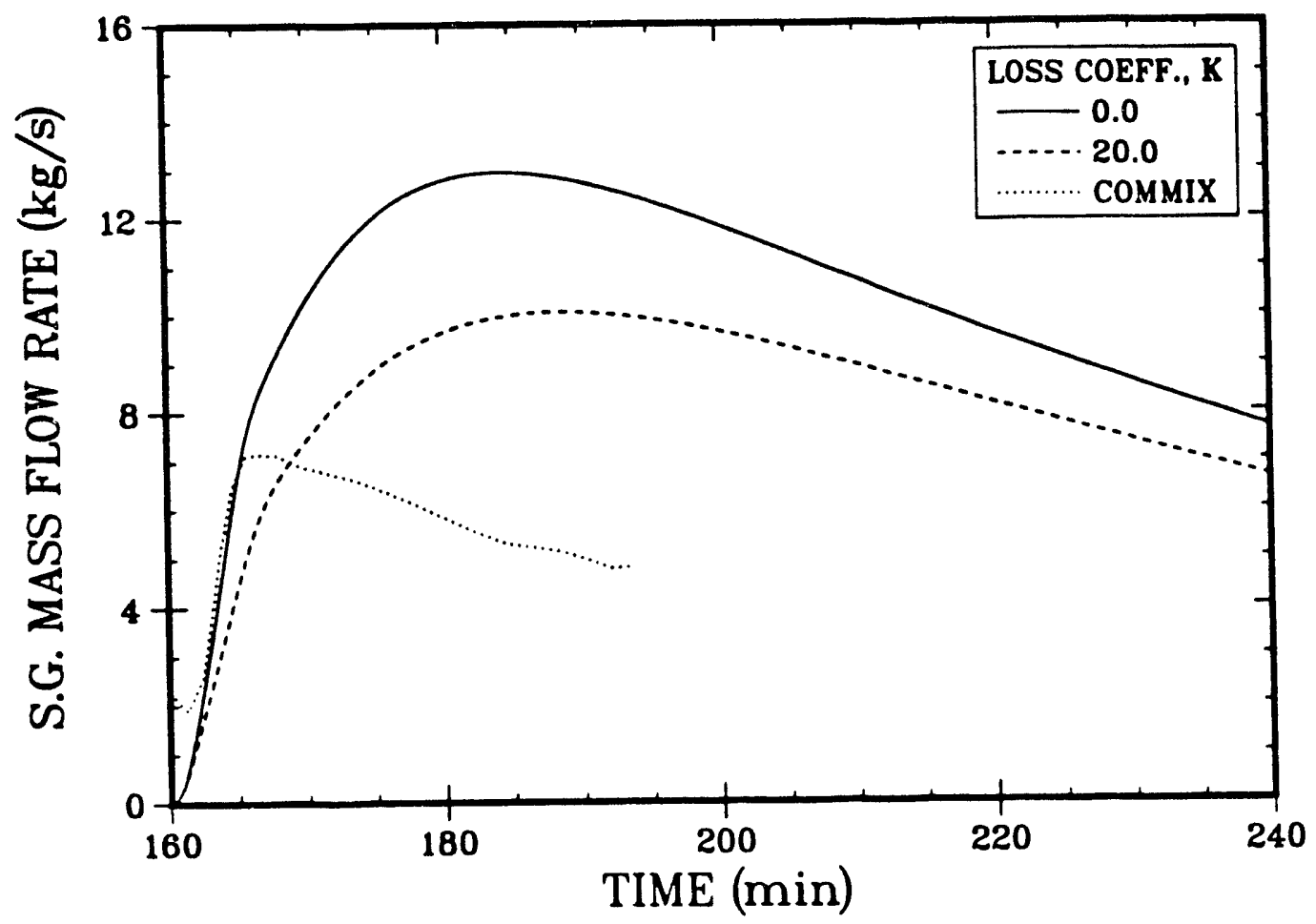

Figure 4.13. Effect of loss coefficient on steam generator flow rate, $\Pi=(8.85,0.9,0.54,0.5)$. 


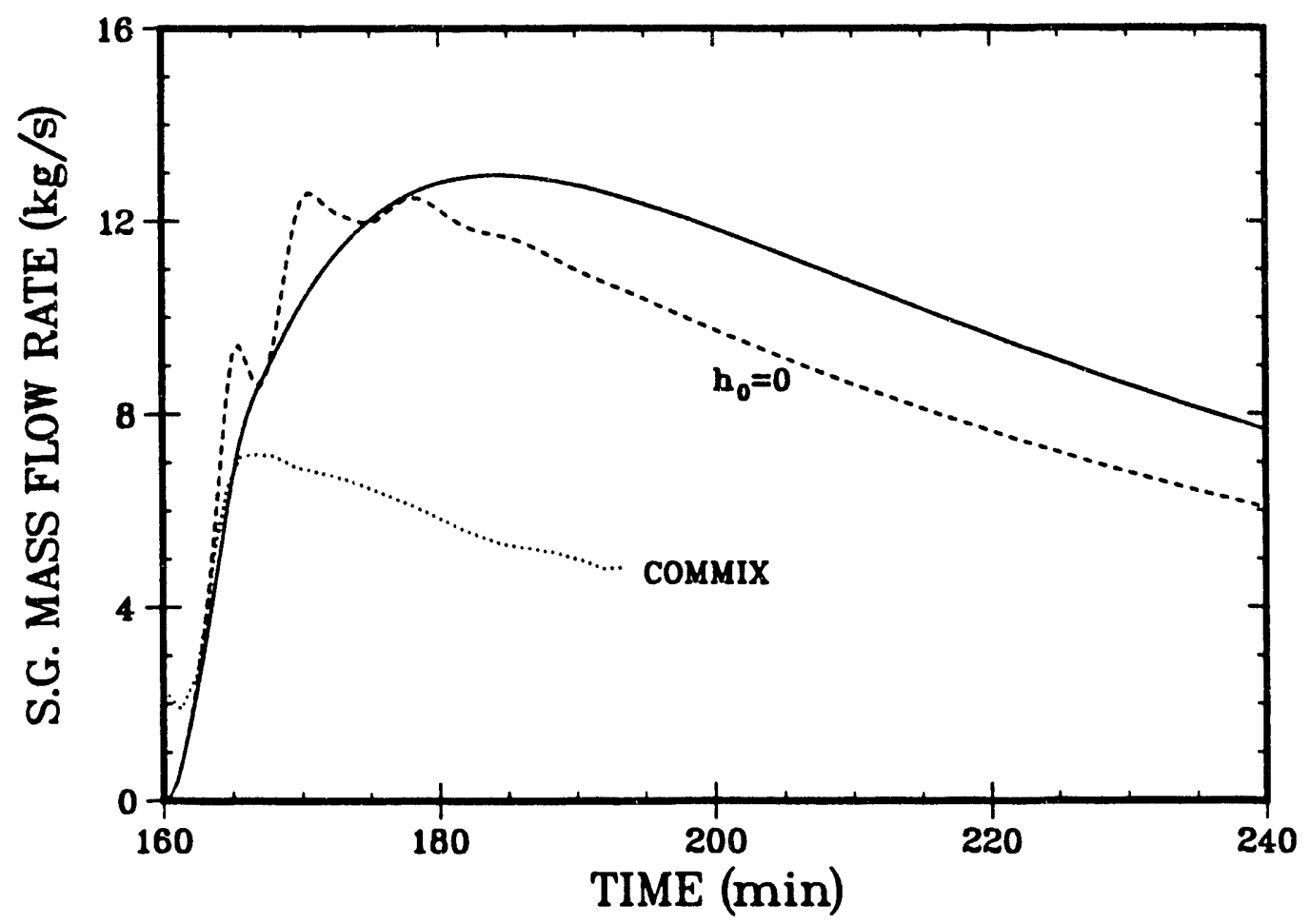

Figure 4.14. Effect of secondary side heat transfer on steam geuerator flow rate, $\Pi=(8.85,0.9,0.54,0.5)$.

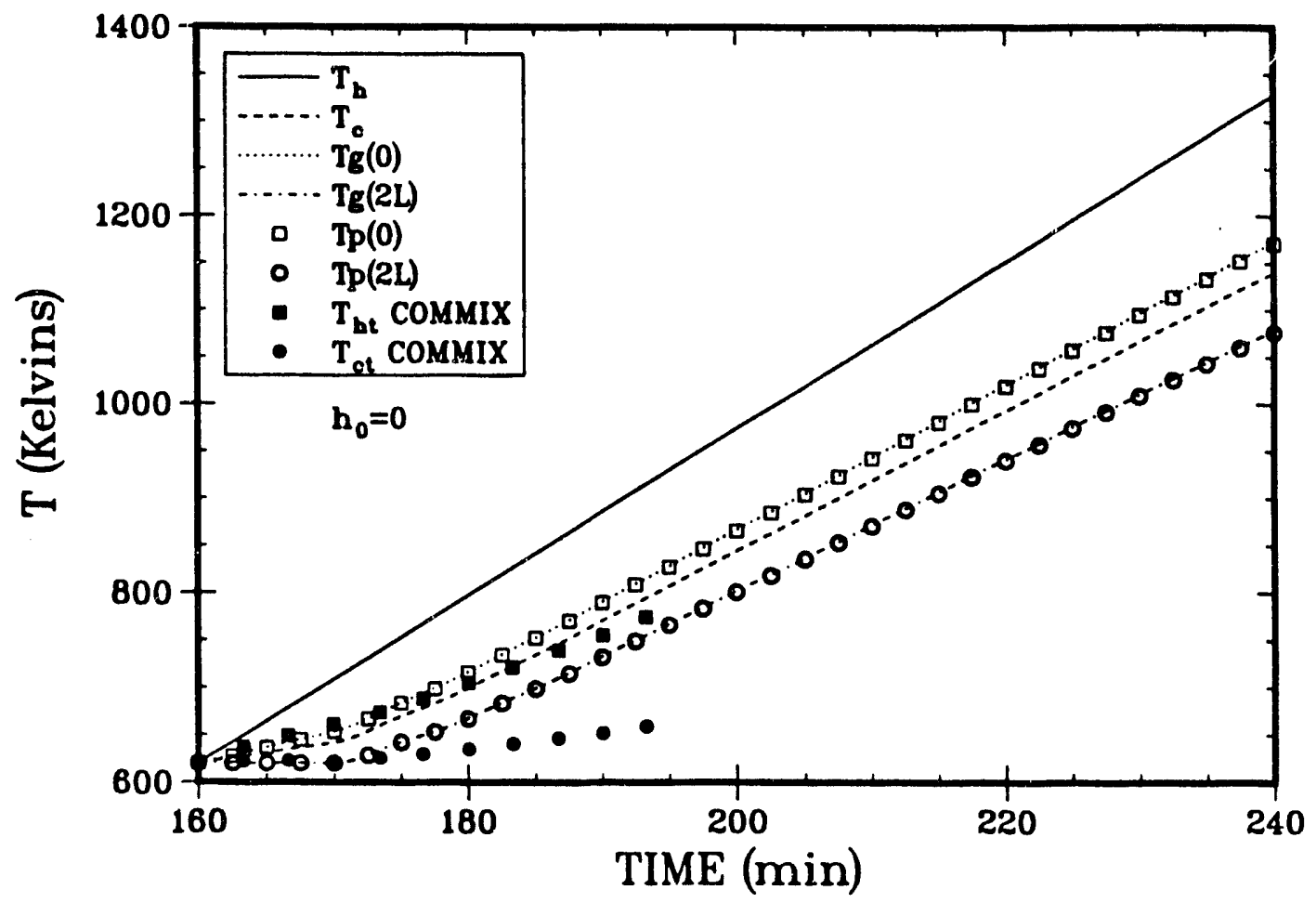

Figure 4.15. Temperature history without secondary side heat transfer, $\boldsymbol{\Pi}=(8.85,0.9,0.54,0.5)$. 


\section{Conclusions}

In this analysis, we present a model of the buoyancy-driven flow in a steam generator for a specified heating rate of gases entering the inlet plenum. The motivation for this analysis was twofold: 1) to provide an independent study of the relation between steam temperatures in the inlet plenum and steam generator circulation rates, 2) and to provide a computationally efficient model to study the effects of variation of key parameters affecting the circulation rate. The key parameters include the heating rate of gases entering the inlet plenum, $r$, the fraction of incoming gases which mix in the inlet plenum before entering the steam generator tubes, $f_{m i x}$, the ratio of forward-flowing to backwardflowing tubes in the steam generator, $n_{r}$, and the hot leg to steam generator mass flow rate, $m_{r}$.

Using the mixing parameters determined by Bayless, viz., $r=8.85 \mathrm{Kelvin} / \mathrm{min}$, $f_{\text {mix }}=0.9, n_{r}=0.54$, and $m_{r}=0.5$, we piedict a similar mass flow rate history for the steam generator. However, the heat transfer rate from the circulating steam to the steam on the secondary side is apparently much less than predicted by Bayless using S/R5. Furthermore, Bayless produced these mass flow rates by specifying artificially large loss coefficients in the hot-leg/steam generator system. According to Bayless, these loss coefficients were specified to match heat transfer rates with the COMMIX simulations. Our study with loss coefficients does show a modest increase in the temperature difference across the SG. However, the introduction of a loss coefficient results in a $10-25 \%$ reduction in mass flow rate. Thus, by increasing the loss coefficient, we will eventually match the circulation rate given by COMMIX, but not the heat transfer rate. It should be reemphasized that the COMMIX simulation assumed insulated SG tubing. Hence, it is not suprising that the heat transfer rates should differ.

This is perhaps the same dilemma faced by Bayless, i.e., having the ability to match either the mass flow rate or the heat transfer rate of COMMIX, but not both. Given that the COMMIX simulation assumed insulated SG tubing, it is somewhat surprising that Bayless would choose to match heat transfer rates. Since the thermcsyphoning phenomena is buoyancy-driven, the heat and momentum transport are intimately coupled. There would seem to be a significant uncertainty between calculations which are in agreement in either the mass cr heat transfer rates, but not boith.

As regards the sensitivity of the model to the various parameters, we can summarize our findings as follows:

- The temperature difference across the SG increases about proportionally with the heating rate. The steam is cooled to its exiting temperature over the rising half of the forward-flowing tubes, and is uniform in temperature thereafter.

- The mass flow rate in the $\mathrm{SG}$ initially increases with heating rate, but ultimately decreases with increasing heating rate. 
- The SG mass flow rate is relatively insensitive to the mixing fraction $f_{m i x}$ and the mass flow rate ratio $m_{i L L} / m_{S G}$. However, both increased mixing and increased flcw ratio tend to increase the temperature of the circulating steam. The temperature difference across the steam generator also increases with increasing $m_{r}$.

- The SG mass flow rate is sensitive to the tube ratio for $n_{r}<0.25$.

- Application of a loss coefficient $(K=20)$ reduces the flow rate and decreases steam temperatures but only mildly increases the temperature difference between incoming and exiting steam.

- Neglect of secondary side heat exchange reduces the mass flow rate in the SG, increases overall vapor temperatures, but decreases the temperature difference across the SG. 


\section{References}

1. Bayless, P. D., 'Analysis of natural circulation during a Surry station blackout using SCDAP/RELAP5,' NUREG/CR-5214,(EGG-2547), EG\&G Idaho Inc., September, 1988.

2. Bejan, A., and Rossie, A. N., 'Natural convection in horizontal duct connecting two fluid reservoirs,' ASME: Journal of Heat Transfer, 103, 108-113, 1981.

3. Cha, Y.S., Domanus, H. M., and Sha, W. T., 'Numerical simulation of mixing in the inlet plenum of the Westinghouse $1 / 7$ scale steam generator model,' $A N L / A T H R P$ 40, Argonne National Laboratory, Àrgonne, IL, January, 1990.

4. Domanus, H. M., et al., 'COMMIX-1B: A three-dimensional transient single-phase computer program for thermal hydraulic analysis of single and multicomponent systems. Volume I: Equations and Numerics; Volume II: User's Manual,' NUREG/CR4348, ANL-85-42, September, 1985.

5. Domanus, H. M., and Sha, W. T., 'Analysis of natural-convection phenomena in a 3-Loop PWR during a TMLB' transient using the COMMIX code,' NUREG/CR5070, ANL-87-54, Argonne National Laboratory, Argonne, IL, January, 1988.

6. Greif, R., Zvirin, Y., and Mertol, A., 'The transient and stability behavior of a natural convection loop,' ASME: Journal of Heat Transfer, 101, 684-688, 1979.

7. Hart, J. E., 'A new analysis of the closed loop thermosyphon,' International Journal of Heat and Mass Transfer, 27(1), 125-136, 1984.

8. Haskell, K. H., Vandevender, W. H., and Walton, L. E., 'The SLATEC common mathematics subprogram library: SNLA implementation, SAND80-2792, Sandia National Laboratories, Albuquerque, New Mexico, 1980.

9. Hyman, J. M., 'Method of lines approach to the numerical solution of conservation laws,' LA-UR-79-837, Los Alamos Scientific Laboratory, Los Alamos, New Mexico, 1979.

10. Kays, W. M., and Crawford, M. E., Convective Heat and Mass Transfer, 2nd. Ed., McGraw Hill, New York, 1980.

11. Martinez, G. M., Gross, R. J., Martinez, M. J., and Rightley, G. S., 'Independent review of SCDAP/RELAP5 natural circulation calculations,' SA ND91-2089, Sandia National Laboratories, Albuquerque, New Mexico. (to be published)

12. Sanders, J., 'Stability of single phase naturai circulation with inverted U-tube steam generators,' Natural Circulation, Kim, J. H., and Hassan, Y. A., Eds., ASME Fluids Engineering Division. FED Vol. 61, 129-139, 1987. 
13. Shampine, L. F., and Watts, H. A., 'DEPAC - Design of a user oriented package of ODE solvers, SAND79-2374, Sandia National Laboratories, Albuquerque, New Mexico, 1980.

14. Stewart, W. A., Pieczynski, A. T., and Srinivas, V., 'Experiments on natural circulation flows in steam generators during severe accidents,' Proc. of Int. ANS/ENS Topical Mecting on Thermal Reactor Safety, San Diego, CA, pp. XIX.6-1, XIX.6-8, February 2-6, 1986.

15. Summers, R. M., et al., 'MELCOR 1.8.0: A computer code for nuclear reactor severe accident source term and risk assessment analyses,' NUREG/CR-5531, SAND90-0364, Sandia National Laboratories, Albuquerque, New Mexico, January, 1991.

16. Torrance, K. E., 'Open-loop thermosyphons with geological applications,' $A S M E$ : Journal of Heat Transfer, 101, 677-683, 1979. 


\section{Distribution:}

Accident Evaluation Branch (2)

Office of Nuclear Regulatory Research U. S. Nuclear Regulatory Commission M/S NLN344

Washington, D.C. 20555

F. Eltawila, M/S NLN-344

Y. S. Chen, M/S NLN-344

Prof. R. Greif

University of California

Department of Mechanical Engineering

Berkeley, California 94720

\section{Internal Distribution:}

1510 J. C. Cummings

1511 J. S. Rottler

1511 M. J. Martinez (10)

1512 A. C. Ratzel

1513 R. D. Skocypec

1513 V. F. Nicolette

1550 C. W. Peterson

6401 J. E. Kelly

6410 D. A. Dahlgren

6412 S. E. Dingman

6413 F. T. Harper

6413 G. S. Rightiey

6418 S. L. Thompson

6418 E. A. Boucheron

6418 R. K. Cole

6418 R. J. Gross

6418 L. N. Kmetyk

6418 G. M. Martinez (10)

6422 N. E. Bixler

6422 T. J. Heames

3141 S. A. Landenberger (5)

3145 Document Processing

for DOE/OSTI (8)

3151 G. C. Claycomb (3)

8.523-2 Central Technical Files 

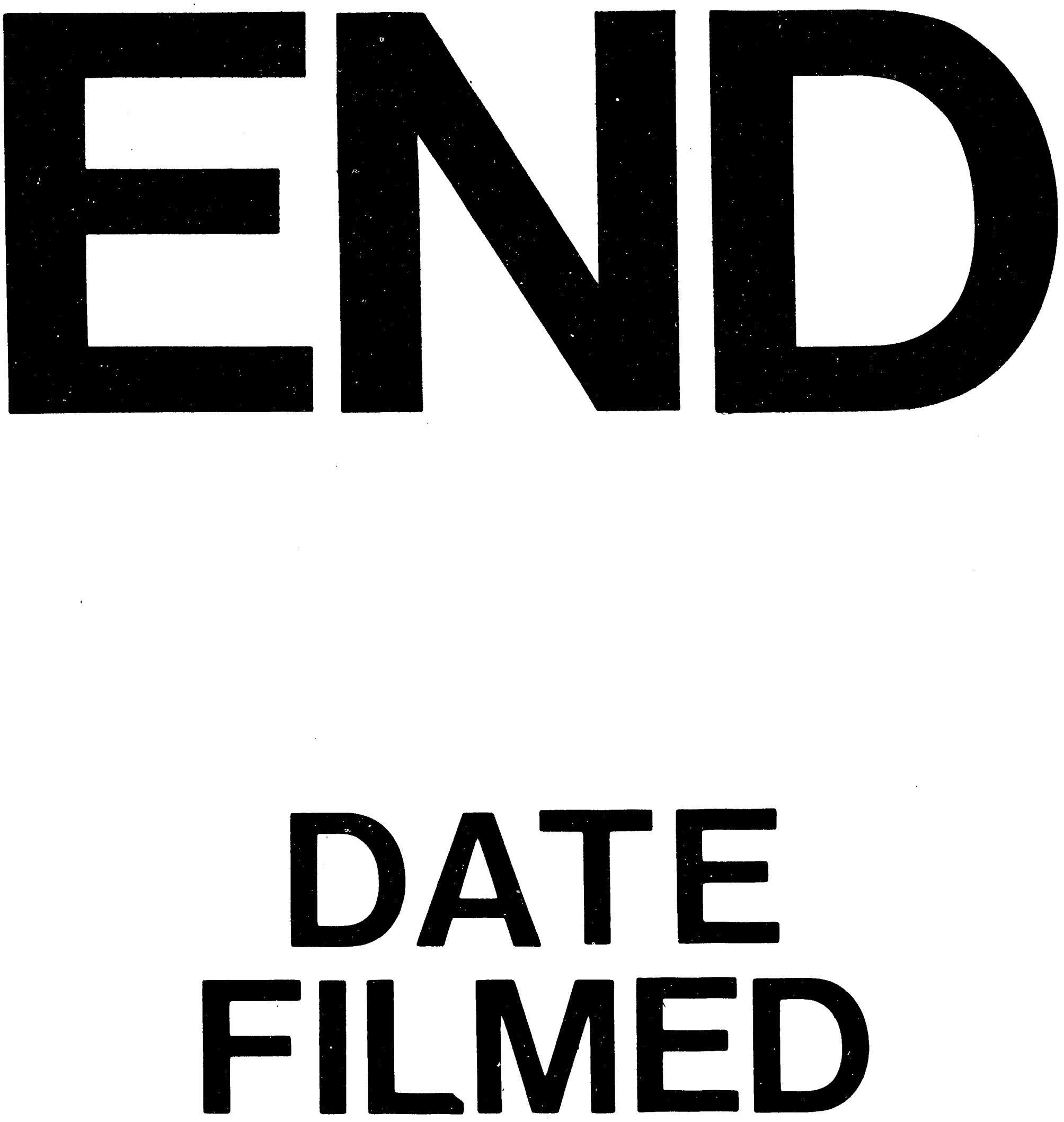

1

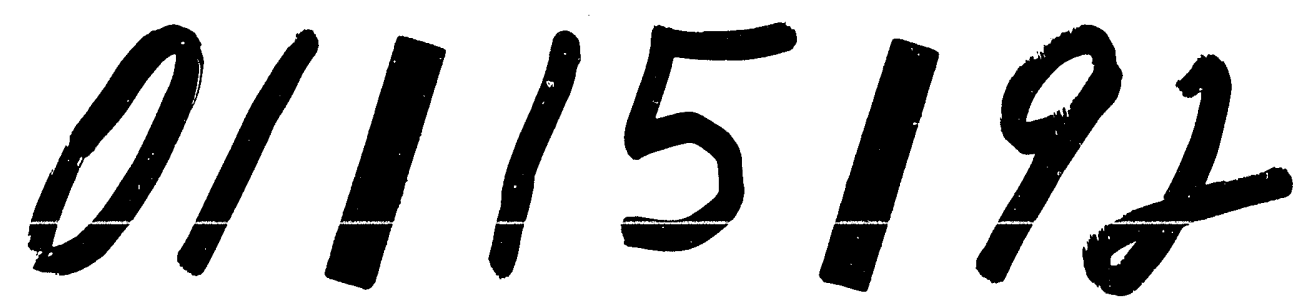


